\title{
Early Feeding Experiences of Families Whose Children Were Born with Cleft Lip andor Palate: A Rural Perspective
}

\author{
Meghan Snyder
}

Follow this and additional works at: https://researchrepository.wvu.edu/etd

\section{Recommended Citation}

Snyder, Meghan, "Early Feeding Experiences of Families Whose Children Were Born with Cleft Lip andor Palate: A Rural Perspective" (2017). Graduate Theses, Dissertations, and Problem Reports. 6683. https://researchrepository.wvu.edu/etd/6683

This Thesis is protected by copyright and/or related rights. It has been brought to you by the The Research Repository @ WVU with permission from the rights-holder(s). You are free to use this Thesis in any way that is permitted by the copyright and related rights legislation that applies to your use. For other uses you must obtain permission from the rights-holder(s) directly, unless additional rights are indicated by a Creative Commons license in the record and/ or on the work itself. This Thesis has been accepted for inclusion in WVU Graduate Theses, Dissertations, and Problem Reports collection by an authorized administrator of The Research Repository @ WVU. For more information, please contact researchrepository@mail.wvu.edu. 


\title{
Early Feeding Experiences of Families Whose Children Were Born with Cleft Lip and/or Palate: A Rural Perspective
}

\author{
Meghan Snyder \\ Thesis submitted \\ to the College of Education and Human Services \\ at West Virginia University
}

in partial fulfillment of the requirements for the degree of

Master of Science in

The Department of Communication Sciences and Disorders

\author{
Dennis Ruscello, Ph.D., Chair \\ Kimberly M. Meigh, Ph.D. \\ Michelle Moore, Ph.D.
}

Department of Communication Sciences and Disorders

\author{
Morgantown, West Virginia \\ 2016
}

Keywords: Cleft Palate, Feeding, Parents, Rural

Copyright 2016 Meghan Snyder 


\title{
Abstract \\ Early Feeding Experiences of Families Whose Children Were Born with Cleft Lip and/or Palate: A Rural Perspective
}

\author{
Meghan Snyder
}

An initial problem frequently found in children born with cleft palate is difficulty feeding. This problem can be magnified in rural areas where healthcare resources are limited. A 29-item questionnaire was developed and administered to 24 families whose children were born with a cleft palate. Many parents experienced difficulties in both instruction and in feeding their children. It was necessary for them to seek information and assistance from different sources. As a result of the findings, an informational pamphlet was developed and distributed to various rural hospitals located in West Virginia, so that information and sources of instruction for feeding were more readily available. 


\section{Table of Contents}

Chapter I: Review of Literature ................................................................................................... 1

Background.................................................................................................................... 1

Figure 1-1. Examples of children with clefts of the primary (left) and secondary palate

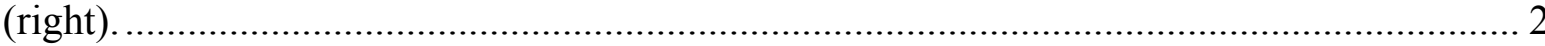

Course of Treatment ...................................................................................................................... 3

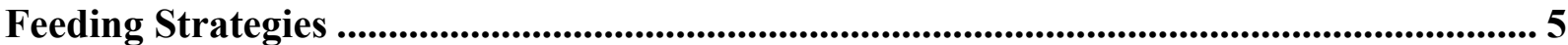

Figure 2-1. Haberman and Mead-Johnson bottles................................................................ 7

Feeding Issues .............................................................................................................................. 10

Rural Healthcare ........................................................................................................................... 11

Statement of Problem....................................................................................................................... 12

Chapter II: Methods ....................................................................................................................... 14

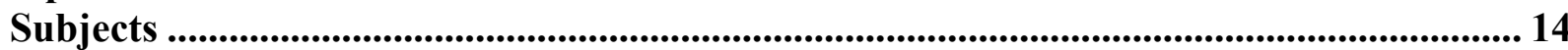

Figure 1-2. Overview of Criteria, Procedures, and Analysis................................................ 15

Confidentiality Procedure ................................................................................................................. 15

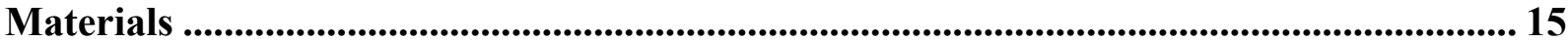

Research Strategy ........................................................................................................................... 22

Figure 2-2. Content that will be incorporated into an informational pamphlet..................... 23

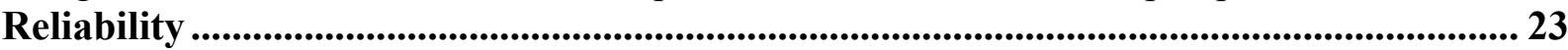

Chapter III: Results ..................................................................................................................... 25

Demographic Information ............................................................................................................... 25

Figure 1-3. West Virginia State Map........................................................................... 26

Figure 2-3. Demographic information questions employed in the survey.......................... 26

Background Information............................................................................................................ 27

Figure 3-3. Background information questions used in the survey .................................. 28

Newborn Feeding....................................................................................................................... 28

Figure 4-3. Satisfaction with initial services received regarding infant feeding.................. 29

Early Feeding Experiences ............................................................................................................... 29

Figure 5-3. Number of reported parental complaints across categories of feeding issues. ... 30

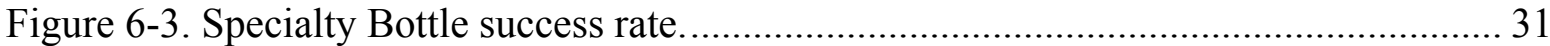

Figure 7-3. Satisfaction with overall feeding experience during first month of birth........... 32

Figure 8-3. Newborn feeding questions used in the survey. ............................................... 34

Breastfeeding ..................................................................................................................................... 34

Figure 9-3. Breastfeeding questions used in the survey....................................................... 34

WVU Cleft Palate Clinic.................................................................................................................. 34

Figure 10-3. WVU Cleft Palate Clinic Satisfaction questions used in the survey. ................ 35

Additional Comments ........................................................................................................................ 35

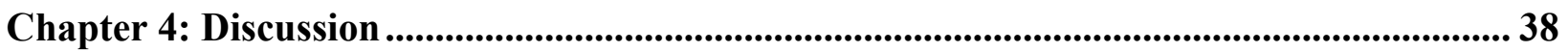

Demographics ......................................................................................................................... 38

Background Information ............................................................................................................... 39

Newborn Feeding.......................................................................................................................... 39

Early Feeding Experiences .............................................................................................................. 41

Breastfeeding ............................................................................................................................................... 42

WVU Cleft Palate Clinic...................................................................................................................... 43 


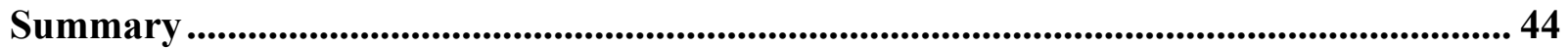

Appendix A: Consent Form ........................................................................................................... 46

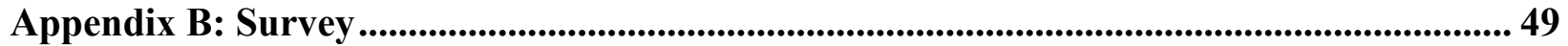

Appendix C: Informative Pamphlet ............................................................................ 54

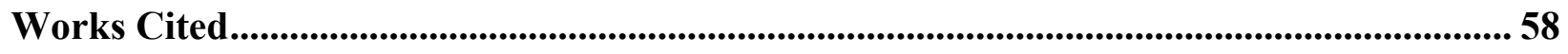




\section{$\underline{\text { Acknowledgments }}$}

I would like to thank the WVU Cleft Palate Center, located at Ruby Memorial Hospital, and all the participants in the study. I would like to thank my thesis advisor, Dr. Dennis Ruscello, for all of the ongoing support, guidance, and encouragement. I would also like to thank my thesis committee team members Drs. Kimberly Meigh and Michelle Moore for their help, time, and support. I would also like to acknowledge and recognize Drs. Linda Vallino-Napoli and David Zajac for their consultation and recommendations. 


\section{Chapter I: Review of Literature}

\section{Background}

Cleft lip with or without cleft palate is the most common facial anomaly in newborn infants, affecting one in every 500 to 1,000 births worldwide (Murray, 1995). This craniofacial malformation occurs during the early embryological period when the palatal shelves and alveolar process are fusing to form the upper lip and hard and soft palates. A cleft lip and/or palate can present in a number of different variations that include isolated clefts of the lip or palate and complete clefts of the lip and palate. The most generally accepted cleft classification system was developed by Kernahan and Stark (1958) and is used universally. The researchers utilized an embryological categorization to describe clefts of the lip and palate by using the incisive foramen as the anatomical marker dividing the primary palate from the secondary palate (Liu, et al., 2007). This classification system describes the most common occurring types of clefts. Clefts of the lip and premaxilla are termed clefts on the primary palate (Millard, 1980). Clefts of the hard and soft palate posterior to the incisive foramen are termed clefts of the secondary palate (Millard, 1980). Further description, such as "left" and "right" and "complete" and "incomplete", were also added to give a more detailed description of the cleft (Liu, et al., 2007). Please see Figure 1-1. 


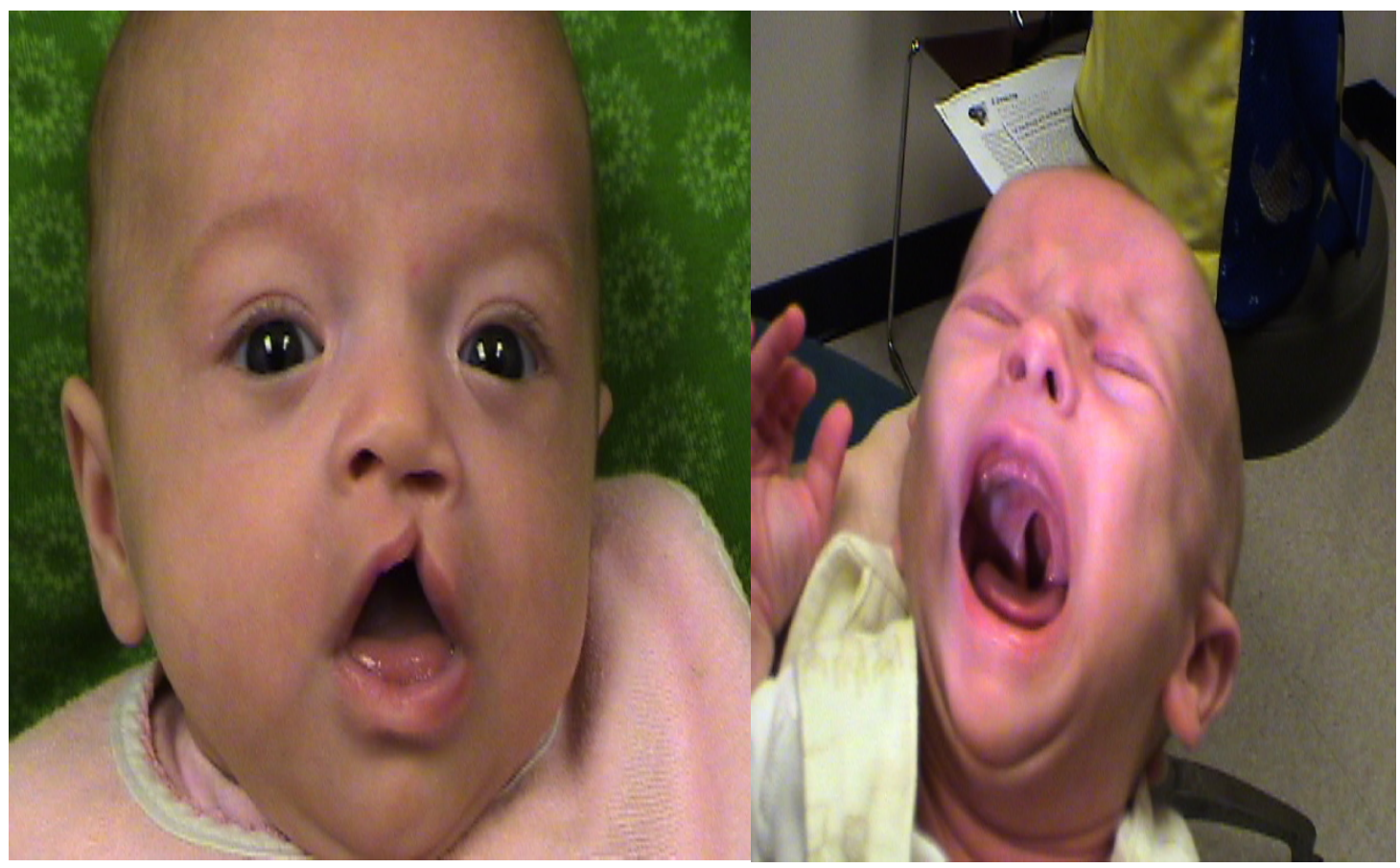

Figure 1-1. Examples of children with clefts of the primary (left) and secondary palate (right).

Isolated or nonsyndromic cleft lip and palate (CL/P) refers to a cleft that is not associated with a major defect or multiple anomalies. The primary hypothesized cause of isolated CL/P is the interaction of genetic and environmental risk factors, which is known as the multifactorial theory of clefting (Vallino, 2017). Syndromic clefting refers to a cleft condition that is associated with two or more anomalies. In this case, the cleft is a feature within the complex of symptoms. The cause is generally genetic-based and may involve a single gene mutation, chromosome abnormality or teratogen (Peterson-Falzone, Hardin-Jones, \& Karnell, 2010). That is, a cleft is not seen in isolation, but is rather a symptom of a larger complex of problems.

Some of the more common multi-anomaly disorders that are linked with clefts include Van Der Woude Syndrome, Pierre Robin Sequence, Stickler Syndrome, Fetal Alcohol Syndrome, and Velocardiofacial Syndrome (Peterson-Falzone et al., 2010). The Online Mendelian Inheritance of Man (OMIM) lists over 400 syndromes that are associated with cleft lip and/or palate (McKusick, 1998). In summary, approximately 60\% of clefts are isolated in 
nature, while the remaining $40 \%$ are attributed to multiple-anomaly problems such as syndromes, sequences, or associations (Trenouth \& Campbell, 1996)

In general, clefts of the lip and palate occur together more frequently than cleft lip or cleft palate only. According to the Center for Disease Control, about 2,650 babies are born with a cleft palate, and 4,400 are born with a cleft lip and palate each year in the United States (Center for Disease Control and Prevention, 2015). The frequency of occurrence in any given population is influenced by a variety of different factors, such as, gender, race/ethnicity, family history, socioeconomic level, and exposure to certain substances during pregnancy (Murray, 1995).

\section{Course of Treatment}

The top priority for children with a cleft immediately after birth is to insure that there are no airway issues or feeding problems so that the baby can grow and develop (Zajac, 2017). After a period of growth and development, a surgical repair plan will be implemented by the surgeon in consultation with other members of the cleft palate team and the child's caregivers (PetersonFalzone et al., 2010). If there is a cleft of the lip, closure typically takes place around three months of age. Repair of the palate will occur at a later time. Closure of the palate is delayed to ensure appropriate skeletal growth of the face (Peterson-Falzone et al., 2010). During the time between birth and surgery, it is essential to make sure a child with a cleft lip and palate is receiving the proper nutrients they need to grow and thrive. Infants with clefts frequently exhibit problems with early weight gain and growth. This is often attributed to difficulties establishing an adequate suckle-and-swallow sequence due to negative intraoral pressure caused by the open cleft (Peterson-Falzone, et al., 2010).

In a study conducted by Sree Devi and his associates (2012), it was found that $73 \%$ of infants with a cleft palate had moderate to severe feeding difficulties related to their reduced 
sucking efficiency. The most notable problems seen are insufficient suction, excessive air intake, choking, nasal regurgitation, fatigue, inadequate milk intake, failure to gain weight, and excessive time required to feed. Inability to feed satisfactorily can lead to maternal stress and anxiety, and thus, lead to poor mother and infant bonding. Immediately after birth it is important that the child's caregivers develop a satisfactory feeding technique that will provide proper nutrition.

At birth, an infant is primed to innately seek out and suckle at the mother's breast. The upper airway of the child is anatomically designed to facilitate feeding, and the tongue is positioned moderately forward occupying most of the oral cavity. The larynx is relatively high, and the epiglottis approximates the soft palate. However, when a child is born with a cleft lip and/or palate these anatomical structures are altered, making the feeding process for the mother and child potentially difficult (Zajac, 2017).

Most often, babies with CL/P experience problems during the oral stage of feeding. Wide clefts involving the lip can impede the infant in achieving a complete seal around the nipple to initiate feeding. If a cleft extends into the alveolar ridge it may further obstruct sealing the nipple. Due to the lack of alveolar bone, the infant may not be able to efficiently compress the base of the nipple against a hard surface. This can become even more difficult if the infant has a bilateral cleft of the primary palate and lacks substantial bone and tissue. Clefts of the secondary palate severely limit the generation of positive and negative pressure required for breast and bottle-feeding, due to the lack of palatal bone. The infant is unable to compress the nipple against the hard palate to expel milk. Negative pressure of the oral cavity is also not generated, leading to large volumes of air in the stomach. In addition, reflux of milk and formula into the open nasal cavity commonly occurs if the baby is fed in the prone position (Zajac, 2017) 
In addition to difficulties in the oral stages of feeding, infants with CL/P may also experience complications with the pharyngeal stage, as well; however, there is some disagreement about whether or not this actually happens. Some authors report symptoms that may suggest reduced airway protection, such as choking when taking in liquids and an increased incidence of chest infections (Zickefoose, 1957; Jeffery \& Boorman, 2001; Young, O'Riordian, Goldstein, \& Robin, 2001). Masarei (2003) reported the results of a consecutive series of videofluoroscopic studies conducted on infants with CL/P, which showed both oral and pharyngeal stage abnormalities for all infants assessed. Conversely, others report that infants with CL/P do not show pharyngeal stage problems but present with only oral stage problems (Borgan, Foulner, \& Turner, 1987).

\section{Feeding Strategies}

Education and reassurance are the first steps to employ with a mother regarding feeding an infant with a cleft. The mother needs to understand the mechanics of infant feeding, and learn ways to circumvent the infant's limitations in generating sucking pressure. The hospital nurse, lactation consultant, or a speech-language pathologist who specializes in feeding can carry out the initial education. Regardless of the healthcare professional, the primary focus is to teach the mother feeding techniques that will result in successful feeding and weight gain for the infant, with the least stress experienced by the infant and family (Reid, 2004). In a study performed by Richard (1994), it was shown that a holistic approach to feeding that incorporates parental education, can lead to improved growth at the time of surgery when compared to groups who received no parental education. The author's data consisted of 233 questionnaires sent to families of infants with CL/P who had either received holistic feeding instructions or did not. 
To maximize the flow of formula, special bottles and nipples were developed for children with CL/P. The nipples on these special bottles deliver an increased rate of formula flow to the infant or allow the feeder to manually assist the infant by squeezing the bottle or nipple. Some of the most commonly used specialized bottles are the Haberman Feeder, Mead-Johnson Enfamil Cleft Palate Nurser, the Pigeon Bottle, and Dr. Brown's Natural Flow Bottle (Zajac, 2017). Some craniofacial centers promote the use of regular nipples and bottles and simply instruct the mother how to make modifications that will facilitate feeding. Please see Figure 2-1 for examples of the Haberman and Mead-Johnson feeding systems.

The Haberman Feeder was created by a mother in England who had a daughter with a cleft palate. This feeder was designed to compensate for the infant's inability to create suction (Hansen, Cook, \& Ahmad, 2016). A long, soft nipple with a slit opening is housed at the end of a reservoir, and a one-way valve is placed between the nipple/reservoir and bottle to prevent formula from re-entering the bottle (Reid, 2004). Compression by the tongue or gums opens the slit and allows formula to flow into the infant's mouth. This bottle can be positioned in the infant's mouth to provide different rates of flow. If the slit is positioned perpendicular to the force of compression, it opens maximally. When the slit is positioned parallel to the force of compression it opens minimally. The slit configuration also closes the nipple following the release of compression, stopping the flow of formula and giving the infant a chance to swallow (Zajac, 2017). This bottle also gives the mother the option to manually assist the baby in compressions by squeezing the reservoir. These compressions must be timed to the natural rhythm of the infant and stopped occasionally to allow the infant to swallow. In a small series of case studies ( $n=6$ ) conducted by Campbell and Trenouth (1987), it was reported that babies using 
these bottles experienced faster feeding times, less vomiting, satisfactory weight gain, and parental acceptance.

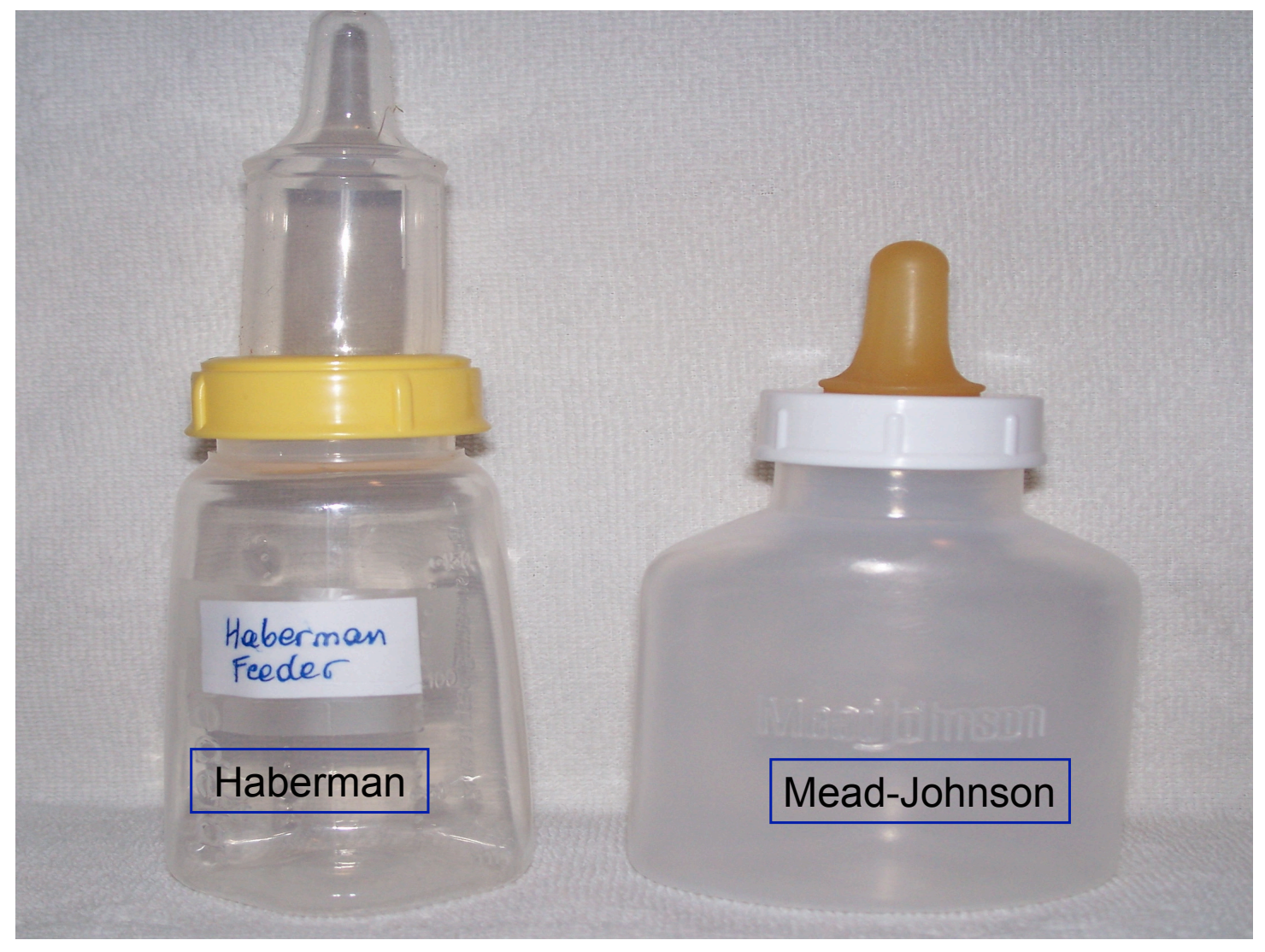

Figure 2-1. Haberman and Mead-Johnson bottles.

The Mead-Johnson Enfamil Cleft Palate Nurser is a low-cost alternative bottle. It has a soft, long, cross-cut (x-shaped) nipple that attaches to a squeezable bottle. This bottle requires assisted squeezing by the caregiver, which may allow for more precision in the flow rate and amount of formula (Miller \& Kummer, 2008).

The Pigeon Bottle is a bottle that also uses a one-way valve and special nipple design to facilitate feeding for a child with CL/P. However, this nipple is shorter in length and has no reservoir. The nipple is also Y-Cut, and is stiffer on one side than the other. The stiff side of the nipple is to be positioned toward the palate to provide a stable surface for compressions of the 
tongue. Similar to the Haberman bottle, the cost of this bottle is relatively high, which can be a problem for some families (Zajac, 2017).

Another bottle that is low-cost, and quickly gaining popularity is the Dr. Brown's Natural Flow Bottle. This bottle is unique because it has an internal venting system, which eliminates nipple collapse and promotes a positive flow. The Dr. Brown bottle is beneficial for infants and bottle-fed children identified with significant problems in taking formula/breast milk during sucking (Handi-Craft Company, 2017). The one-way valve system is similar to that of the Pigeon bottle where it ensures that the formula goes into the mouth rather than back into the bottle. This significantly reduces reflux and gas. Nipples are available in different sizes and flow rates, thus, an infant can gradually increase the rate of formula flow.

Typically, the larger the cleft the harder it is for the baby to generate suction. Thus, infants with larger clefts may benefit from a feeding obturator to aid in oral intake (Hansen, Cook, \& Ahmad, 2016). The obturator nipple has a hood-like attachment to the base of the nipple designed to cover the cleft. This design was created to promote normal sucking, however, this is not always the case due to the flexibility of the hood (Zajac, 2017). Please see Figure 3-1. 


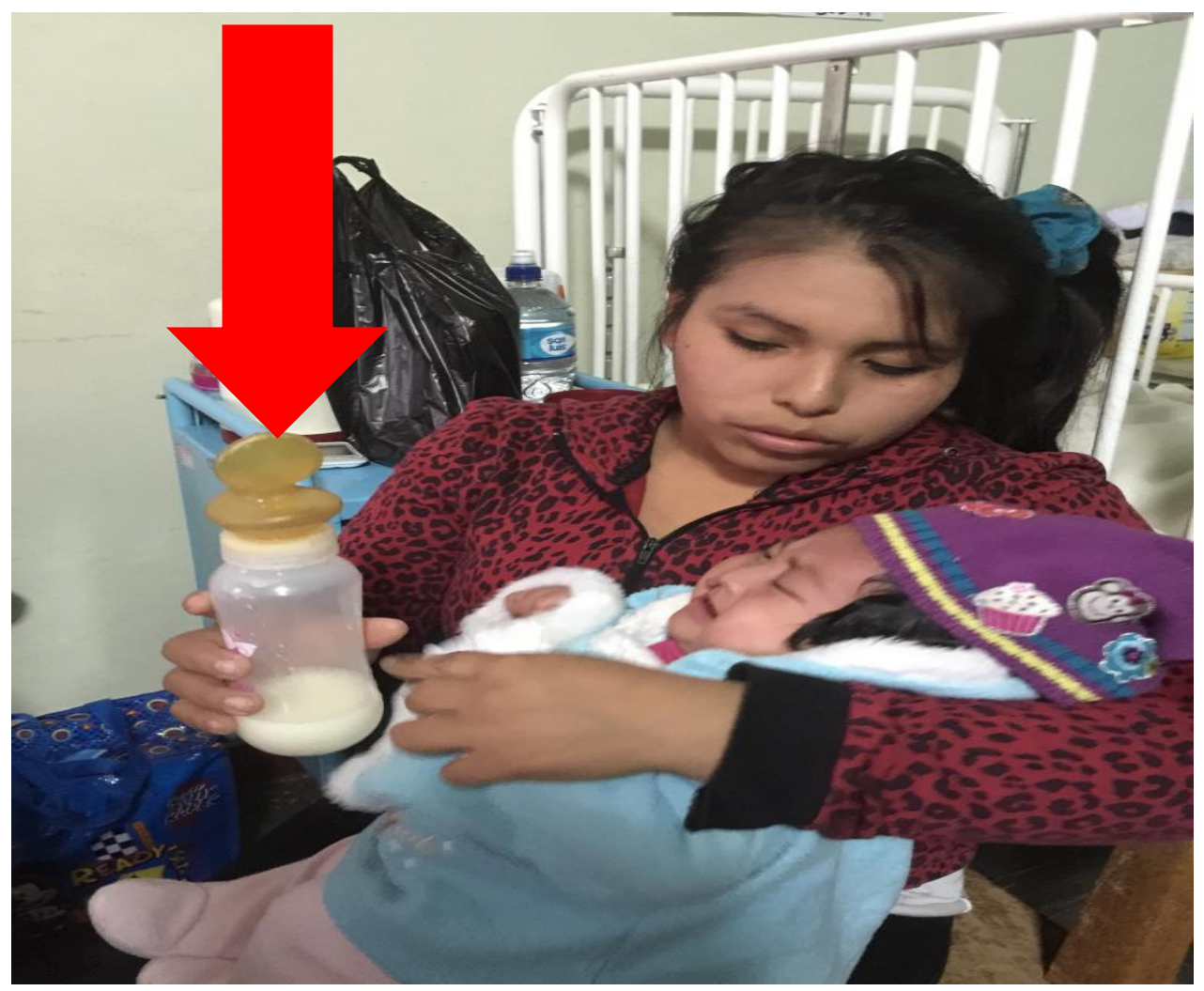

Figure 3-1. Feeding obturator.

Although there are many different bottle and feeding options for mothers to choose from, having success with any of these is dependent on the mother's ability to understand the proper ways to feed her child with a CL/P. The feeding specialist should make sure the mother feels comfortable while feeding her child. The feeding specialist should first advise the mother to hold the bottle in a vertical position. This will allow gravity to assist in the flow of formula. The mother should also be advised to hold her baby upright at a 45-to 60-degree angle. This will decrease the likelihood of reflux of formula into the nasal cavity. The infant's head should be supported in a chin tuck position with arms forward, trunk in midline, and the hips flexed (Miller \& Kummer, 2008). The mother should also be reminded to frequently burp the baby to eliminate excessive intake of air. If the baby has a unilateral cleft of the primary palate, the mother should 
make sure to put the nipple under the non-cleft side of the palate to increase compression pressure by the tongue (Zajac, 2016).

Some mothers still wish to breastfeed, even with the many specialized bottles and nipples available. Often breast feeding will work well if the cleft is of the lip only. The nipple may conform and fill the area of the cleft, or the mother can assist with closing off the lip with her hands (Miller \& Kummer, 2008). If the cleft is confined to just the soft palate, the infant may be able to breastfeed to an extent using the hard palate to make compressions. Also, some infants may learn to use the posterior portion of their tongue to close the oral cavity. This may reduce overall efficiency of the compression generated by the tongue (Zajac, 2016). Infants with a complete cleft are much more likely to have a difficult time with breast feeding due to the fact they will be unable to create negative pressure for suction (Miller \& Kummer, 2008). In a study done by Gil-da-Silva-Lopes (2013), 78\% of mothers were unable to breastfeed if the child had a complete cleft. If a mother is insistent on trying breastfeeding, it is important to closely monitor the baby to ensure that she/he is receiving sufficient nutrients, or the mother can pump breast milk and present via one of the delivery systems discussed.

\section{Feeding Issues}

It is clear that there are a number of different options available to help facilitate feeding for children born with CL/P; however, parents must be aware of these feeding options to make an informed decision on what is best for their child. A study done by Trenouth and Campbell (1996) utilized a questionnaire to obtain information on any problems parents encountered with feeding their newborns with CL/P. The authors received twenty-five out of a possible thirty surveys from respondents. Results showed that of the twelve mothers who attempted to breastfeed none were successful, and fourteen mothers experienced problems with the quantity of food taken and the 
length of time to feed the baby. It was reported that most babies fed better without a feeding obturator unless they had a complete cleft. Most parents used the Haberman Feeder, which proved to have fewer problems with the quantity of food taken in. Almost all of the mothers were dissatisfied with the information they received from their hospitals (Trenouth \& Campbell, Questionnaire evaluation of feeding methods for cleft lip and palate neonates, 1996). Similar results were found in a study done by Oliver and Jones (1997) where 100 families were surveyed, and over 50\% reported that they were unhappy with the feeding support they received. Ninety-five percent of respondents believed that there should be a healthcare worker who was specially trained to give expert feeding help and advice. Unfortunately, healthcare is often limited, and the appropriate information is not readily available to give expert guidance to mothers of newborns with CL/P.

\section{Rural Healthcare}

Globally, healthcare for people in rural areas is generally more problematic when compared with services available for those living in urban areas (Strasser, 2003). Due to a concentration of poverty, low health status, and high burden of disease, there is a need to focus specifically on improving the health of people in these rural communities. Providing for the needs of children with disabilities is even more difficult in rural areas because of geographic barriers, community and family circumstances, sociocultural differences, and personnel recruitment issues (Coleman, Thompson-Smith, Pruitt, \& Richards, 1999). With the demand for speech-language pathologist growing, it is no surprise that many rural communities lack access

to these services (Houn \& Troitter, 2003). Barriers to access pediatric speech-language pathology services limit rural and remote consumers' usage of health services, indicating a possible inequity if compared to larger, more accessible urban areas (Callaghan, McAllister, \& 
Wilson, 2005). Even if access to a speech-language pathologist is available in a rural setting, it has been shown that rural personnel are slightly less experienced than their urban counterparts (Blood, Thomas, Ridenour, \& Hammer, 2002). With these issues considered and the fact that clefting is a low incidence birth anomaly, it is more likely that the family of a child with CL/P who is born in a rural hospital may not have access to initial parent feeding instruction and education.

In a study done by Oliver (1997), which surveyed 100 parents of newborns with CL/P, results showed that there is an unmet need for information, particularly feeding training for parents of children with clefts. Moreover, literature cited in this review suggests that various rural healthcare limitations may interfere with the appropriate care of newborns with cleft palate. The lack of initial feeding assistance for children with various cleft conditions has been reported by parents whose children are seen at the West Virginia University Cleft Palate Clinic; however, there is no empirical data to support the assertion. To date, only anecdotal information exists; however, if such a problem exits, it is imperative to identify the problem and institute a plan to improve services for children and their families.

\section{Statement of Problem}

West Virginia is one of only fifteen rural states in America. To be classified as a rural state, at least $50 \%$ of the population must be living in areas with a population under 50,000 (U.S. Census Bureau, 2010). According to the United State Census Bureau, only ten out of fifty-five counties in the state have a population that exceeds 50,000 . It is evident that the problems discussed earlier regarding rural healthcare exist in West Virginia as well. One of only two treatment centers for children with cleft palate in West Virginia is the WVU Health Sciences Center (HSC) located in Morgantown, WV. Those families who do not live in close proximity to 
the WVU HSC may initially experience problems with feeding, because healthcare personnel in rural areas lack the experience and exposure to feeding issues found in the population of children born with clefts.

The purpose of this study was twofold. First, the initial feeding experiences of families whose children were born with cleft lip and palate, cleft palate only, or cleft lip only were studied. The respondents consisted of families who attended the WVU Cleft Palate Clinic. They were asked to complete a survey regarding their early feeding experiences. Second, their responses were analyzed and feeding issues were identified. As a result, an informational feeding pamphlet for rural healthcare workers was developed to assist personnel in helping parents and their children with early feeding issues. 


\section{Chapter II: Methods}

\section{Subjects}

Subjects for the investigation consisted of parents whose children are patients at the West Virginia University Cleft Palate Clinic. Upon clinic visit, the experimenter inspected each child's medical chart to determine chronological age and cleft classification. Parents were contacted if their child was between the ages of 1 month and eight years of age and presented with an isolated cleft of the secondary palate, a complete unilateral or bilateral cleft of the primary and/or secondary palates, or a cleft lip only. Parents of children who presented with a documented syndrome, sequence, or association, were not be eligible to participate in the survey. If a child met the criteria, the parent(s) were personally contacted at the clinic. The nature and purpose of the study was explained, and if the parent chose to participate in the study, a consent form was signed. The parent then answered the questionnaire in a quiet room located in the Otolaryngology Clinic. The questions were verbally read to the parent by the experimenter. Please see Figure 1-2 for an overview of the criteria, procedures and analysis.

\begin{tabular}{|c|c|c|c|c|}
\hline $\begin{array}{l}\text { Selection } \\
\text { Criteria }\end{array}$ & $\begin{array}{l}\text { Children between the } \\
\text { ages of one month and } \\
\text { eight years of age. }\end{array}$ & $\begin{array}{l}\text { Chart review } \\
\text { was conducted } \\
\text { to determine } \\
\text { eligibility. }\end{array}$ & $\begin{array}{l}\text { Clefts of the } \\
\text { secondary palate } \\
\text { only, unilateral or } \\
\text { bilateral clefts of the } \\
\text { primary and/or } \\
\text { secondary palate, or } \\
\text { cleft lip only. }\end{array}$ & $\begin{array}{l}\text { Exclusion if cleft is } \\
\text { part of a syndrome, } \\
\text { sequence, or } \\
\text { association. }\end{array}$ \\
\hline $\begin{array}{l}\text { Parent } \\
\text { Contact }\end{array}$ & $\begin{array}{l}\text { Parents were } \\
\text { personally contacted at } \\
\text { the clinic, if their child } \\
\text { met the selection } \\
\text { criteria. }\end{array}$ & $\begin{array}{l}\text { The nature and } \\
\text { purpose of the } \\
\text { study was } \\
\text { explained. }\end{array}$ & $\begin{array}{l}\text { If the parent agreed, } \\
\text { she/he signed a } \\
\text { consent form. }\end{array}$ & $\begin{array}{l}\text { The parent answered } \\
\text { the questionnaire in a } \\
\text { quiet room located in } \\
\text { the Otolaryngology } \\
\text { Clinic. The questions } \\
\text { were verbally read to } \\
\text { the parent by the } \\
\text { experimenter. }\end{array}$ \\
\hline $\begin{array}{l}\text { Study } \\
\text { Procedure }\end{array}$ & $\begin{array}{l}\text { The parent verbally } \\
\text { completed the } \\
\text { questionnaire and it }\end{array}$ & $\begin{array}{l}\text { The } \\
\text { questionnaire } \\
\text { was coded by }\end{array}$ & $\begin{array}{l}\text { Responses were } \\
\text { tabulated as obtained } \\
\text { from subjects. }\end{array}$ & $\begin{array}{l}\text { Comments were } \\
\text { categorized as to } \\
\text { specific problems }\end{array}$ \\
\hline
\end{tabular}




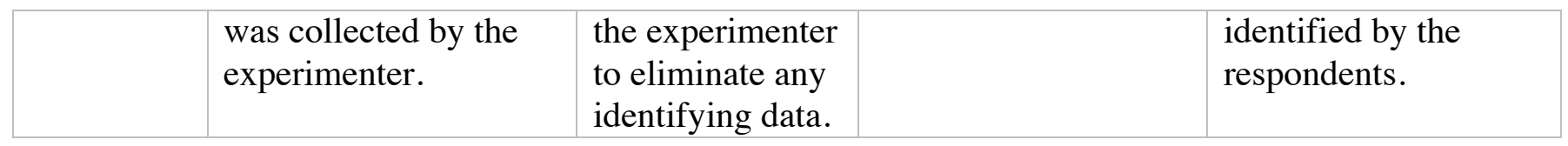

Figure 1-2. Overview of Criteria, Procedures, and Analysis

\section{Confidentiality Procedure}

A total of 24 families agreed to participate in the study. Parents were assigned a number that was entered on the questionnaire. There was no personal identification information that could be used to identify a participant in the investigation. A list was kept by the investigator that contained the names of the participants and the numbers that each participant was assigned. The list was kept in the investigator's office (DMR) and placed in a locked cabinet. At the termination of the investigation, the list will remain in the possession of the experimenter and destroyed at the appropriate time.

Materials

The questionnaire consisted of 29 items across five different information-seeking categories. Responses varied according to the type of information that was sought. While the majority of questions required Yes/No responses, there were also multiple-choice selections, Likert scale items, and short answer completion questions. The instrument required approximately 15-20 minutes to complete.

The construction of the questionnaire was a two-part process. First, existing literature was reviewed. A total of four previous research experiments, which surveyed parents of children with $\mathrm{CL} / \mathrm{P}$ were identified and used as a starting point for development of the questionnaire. The paper by Hutchinson (2005) was the primary source for developing question content. The author researched overall parental satisfaction with cleft services rather than just one specific area such as feeding satisfaction. This made some questions, such as surgery satisfaction, inappropriate for the purposes of the survey. These questions were excluded from the questionnaire. A second 
study that was identified focused exclusively on parental perceptions of feeding infants with cleft lip and/or palate (Oliver \& Jones, Neonatal feeding of infants born with cleft lip and/or palate: Parental perceptions of their experience in South Wales, 1997). This study was limited in the number of questions, and all questions appeared very broad in content. A third paper by Trenouth \& Campbell (1996) was also reviewed to identify potential questions. This study also examined parental evaluation of feeding methods for neonates with cleft lip and/or palate. The final study employed in the development of the questionnaire was conducted by Shuttleworth, Dalton, and Cooper (2014). Although this study focused on creating an overall developmental measure of appraisal for parents of children with clefts, many important topics were discussed. Questions used for evaluation of parental feeding concerns were assessed and some used in the construction of the current questionnaire.

After all research publications were reviewed, questions relevant to the current topic were compiled and the questionnaire was formed. From this initial version, two speech-language pathologists who direct cleft palate clinics in the eastern area of the United States were contacted and asked to review and provide comments concerning the questionnaire. They were chosen because a number of the patients attending their clinics reside in rural areas of the United States, and many of the patients who are followed by the West Virginia University Cleft Palate Clinic reside in defined rural areas. Combined, the two practitioners have approximately 60 years of experience in the management of patients with clefts. Their feedback was reviewed and incorporated into the final questionnaire. Please see Appendix A.

The final questionnaire was divided into six sections. These sections included the following: (1) an introduction that discusses the purpose of the questionnaire, (2) demographic information regarding age, sex, ethnicity, and residence, (3) background information pertaining 
to family history of clefting and awareness of cleft palate, (4) newborn feeding experiences of the patient and mother, (5) breast feeding experiences, if any, and (6) WVU Cleft Palate Clinic feeding experiences. An additional section was added at the end for any anecdotal remarks. Each section is listed below, along with individual rationales for all six sections.

\section{Introduction:}

Dear Parent:

We are interested in learning about your experiences with feeding your child when she/he was just born at the hospital. We kindly ask you to take a few minutes to complete this survey. The information you give us will help us better serve other families who have infants with cleft lip and palate in the future. It is important for you to know that neither you nor your child will be identified in the dissemination of the results.

Thank you for taking the time to complete this survey.

Introduction Rationale: The purpose was to inform parents what was required of them and informing them that their participation was anonymous.

\section{Section I: Demographic Information}

1. My child's age is:

2. My child is:
a. Female
b. Male

3. I (parent) am:
a. Female
b. Male

4. What is your ethnicity?

5. I am a resident of City: County: State: 
Demographic Information Rationale: The purpose was to obtain demographic information that would assist the experimenter in interpreting the results of the survey.

\section{Section II. Background Information.}

6. Do you have a family history of cleft palate?
a. Yes
b. No
c. I don't know

7. Did you have any other prior experience with cleft palate before your child was born?
a. Yes
b. No

8. When was your child first diagnosed with a cleft palate?
a. Before birth
b. Time of birth
c. After leaving the birth hospital

Background Information Rationale: The purpose of this section was to identify any background information the family may or may not have regarding cleft lip and/or palate, and to determine the time of the initial diagnosis.

\section{Section III: Newborn Feeding}

9. At the time of your child's birth, where did you receive information regarding feeding your child?
a. Birth Hospital
b. Cleft Palate Clinic
c. Did not receive instructions
d. Other

10. Which professional(s) provided the feeding instructions at the birth hospital? (Check all that apply)
a. Nurse
b. Occupational Therapist (OT)
c. Speech Pathologist (SLP)
d. Physical Therapist (PT)
e. Lactation Consultant
f. Other 
11. How satisfied were you with the feeding management information and training you received from the birth hospital?
a. Very Satisfied
b. Satisfied
c. Neutral
d. Dissatisfied
e. Very dissatisfied

12. Was it necessary to seek information from another source?
a. Yes
b. No

If yes, please specify:

13. Did you feel prepared to feed your child after birth?
a. Yes
b. No

14. Did your child experience problems with feeding following birth?
a. Yes
b. No

15. If your baby experienced problems, what were they? Please check all that apply.
a. Did not latch to nipple
b. Poor suck
c. Took a limited quantity of food
d. Extended feeding time
e. Food leaking from the nose
f. Excessive coughing
g. Choking
h. Vomiting
i. Reflux
j. Gas

Other:

16. Were you instructed to use a special feeding bottle or nipple?
a. Yes
b. No (If no, skip to number 20)

17. What special bottle or nipple did you use? (Choose all that apply)
a. Haberman Feeder
b. Pigeon Feeding Aid 

c. Dr.Brown Specialty Bottle d. Mead Johnson Cleft Palate Nurser
e. Not Sure
f. Other (please specify)

18. Where did you obtain these bottles or nipples?
a. Pharmacy
b. Birth Hospital
c. Internet
d. Medical Supply Store
e. Cleft Palate Clinic
f. Other

19. Did you experience difficulty obtaining bottles or nipples?
a. Yes
b. No

Is yes, please specify the reason:

20. Was it necessary to change your baby's formula to help your baby gain weight?
a. Yes
b. No

Is yes, please specify the reason:

21. During the first month after birth, was your baby admitted to the hospital because of some feeding problem?
a. Yes
b. No

Is yes, please specify the reason:

22. Overall, how would you describe you and your child's feeding experience during the first month of birth?
a. Very Satisfied
b. Satisfied
c. Neutral
d. Dissatisfied
e. Very dissatisfied

Newborn Feeding Rationale: The purpose of this section was to identify initial problems seen in the newborn feeding of children with cleft palate, if any, identify a list of professionals involved, determine the different methods of feeding and parental satisfaction. 


\section{Section IV: Breastfeeding}

23. Did you consider breastfeeding?
a. Yes
b. No (If no, skip to number 27)

24. Did you meet with a lactation consultant after the birth of your child to attempt breastfeeding?
a. Yes
b. No
c. Not sure

25. Were you encouraged to breastfeed your baby?
a. Yes
b. No

26. If yes, were you successful with breastfeeding?
a. Yes
b. No

Breast Feeding Rationale: The purpose was to collect data on the mother's experiences with breastfeeding, if appropriate.

\section{Section V: WVU Cleft Palate Clinic}

27. When you first visited the WVU Cleft Palate Clinic, was your child's feeding status discussed?
a. Yes
b. No

28. Did the cleft palate team assist you with any feeding needs?
a. Yes
b. No
c. Did not have feeding needs

29. If there was a feeding issue, how satisfied are you with the feeding management information and training you received from the cleft palate team?
a. Very Satisfied
b. Satisfied
c. Neutral
d. Dissatisfied
e. Very dissatisfied 


\section{If there is any additional information that you would like to add, please feel free to}

do so.

\section{Thank you for your participation.}

WVU Cleft Palate Clinic Rationale: The purpose of this section was to collect data on the caregiver's experience with the WVU Cleft Palate Clinic.

\section{Research Strategy}

A survey research strategy was used to obtain information on an important clinical issue (Orlikoff, Schiavetti, \& Metz, 2015). The questionnaire format allowed the collection of data on the early feeding experiences of parents with their children. One issue with questionnaires is the return rate and the introduction of bias, which reflects those persons who completed the instrument. However, our study procedure allowed the collection of data for all parents who met the selection criteria and agreed to participate. This enabled the establishment of a database from the "population" of young children who are enrolled in the WVU Cleft Palate Clinic. It was our contention that the study of early feeding experience is an important professional issue that has implications for both urban and rural cleft palate clinics. The tabulation of individual questions allowed for the identification of trends in early parental/child feeding encounters. Once problems were identified, the collection of these data facilitated the development of feeding guidelines and assistance for professionals who deal with birthing but are unfamiliar with the potential feeding problems of children born with cleft palate in the rural locales of West Virginia.

The results did show a trend that parents were not receiving instruction and encountered problems; consequently, an informational pamphlet was prepared for distribution to all rural 
hospitals located in West Virginia. Based on a review of the literature, the content consisted of the following components: (1) an explanation of feeding and problems that may be experienced by the child and family, (2) feeding techniques that be employed, (3) the selection of appropriate nipples and bottles for the child and (4) internet resources for parents and professionals. Please see Figure 2-2 for additional content information pertaining to each of the major content categories.

\begin{tabular}{|c|c|c|}
\hline $\begin{array}{l}\text { 1. An explanation of feeding } \\
\text { and problems that may be } \\
\text { encountered. }\end{array}$ & $\begin{array}{l}\text { 2. Feeding techniques for the } \\
\text { child with cleft palate. }\end{array}$ & $\begin{array}{l}\text { 3. Selecting an appropriate } \\
\text { nipple and bottle. }\end{array}$ \\
\hline $\begin{array}{l}\text { A. Parent-child bonding } \\
\text { process. } \\
\text { B. Nutritional needs of the } \\
\text { newborn. } \\
\text { C. Feeding goals for the first } \\
\text { month of life. }\end{array}$ & $\begin{array}{l}\text { A. Establish an appropriate } \\
\text { feeding position. } \\
\text { B. Assisting the child in } \\
\text { forming a lip seal. } \\
\text { C. Positioning the nipple in } \\
\text { the mouth. } \\
\text { D. Developing a consistent } \\
\text { feeding schedule. } \\
\text { E. Burping the baby during } \\
\text { feeding. } \\
\text { F. Dealing with nasal } \\
\text { regurgitation. } \\
\text { G. Cleaning the baby's mouth } \\
\text { and nose after feeding. }\end{array}$ & $\begin{array}{l}\text { A. Selecting and modifying } \\
\text { different feeding nipples. } \\
\text { B. Bottling systems most } \\
\text { frequently used. } \\
\text { C. Online demonstration } \\
\text { materials for parents. }\end{array}$ \\
\hline
\end{tabular}

Figure 2-2. Content that will be incorporated into an informational pamphlet.

\section{Reliability}

Prior to administration of surveys at the WVU Cleft Palate Clinic, two simulation surveys were given to volunteers by the examiner (MS). This was done to maintain consistency across administration, and address any final issues before the actual administration of the instrument. In addition, the data were tabulated and the score sheets were re-scored by the thesis advisor (DR) to examine point-by-point inter-judge reliability prior to the beginning of the study. A percentage of agreement was computed to be $95 \%$. After completion of data collection, the 
examiner (MS) re-scored three surveys to examine intra-judge reliability. An inter-judge reliability figure of $97 \%$ was computed. 


\section{Chapter III: Results}

The survey was distributed at the West Virginia University Cleft Palate Clinic located in the Physician's Office Center of Ruby Memorial Hospital between the months of January and March 2017. Twenty-four families elected to participate and completed the surveys. Prior to answering the survey, each parent or legal guardian completed a consent form (See Appendix A), which was first explained to them by the principal investigator, Meghan Snyder. Completed consent forms and surveys were then placed in a locked filling cabinet in the office of the coinvestigator, Dr. Dennis Ruscello.

The survey was divided into six sections. These sections included the following: (1) an introduction, (2) demographic information, (3) background information related to cleft palate, (4) newborn feeding experiences of the patient and caregiver, (5) breast feeding experiences, and (6) WVU Cleft Palate Clinic feeding experiences. Anecdotal notes and stories were orthographically recorded under "additional comments" at the end of each survey. Each section is listed below, with an explanation of the results.

\section{Demographic Information}

Of the twenty-four surveys collected, a father completed one, nineteen were completed by mothers, and four were completed by both mother and father. All twenty-four participants identified their ethnicity as white. Twelve of the children studied were females and twelve were males. Their current ages ranged between 6 months and 7.5 years, with an average age of 3 years, 8 months. The children and their families came from fifteen different counties across the state of West Virginia. These counties were:
(1) Barbour
(1) Berkeley
(1) Gilmer
(1) Grant
(1) Hampshire
(1) Hardy
(3) Marion
(1) Pocahontas 
(3) Nicholas

(1) Randolph

(2) Monongalia
(2) Upshur

(3) Wood

The map below shows the location of the counties in gold with the exception of Monongalia

County, which is coded blue. Monongalia County is the location of the West Virginia University

Cleft Palate Clinic at the Health Sciences Center. Please see Figures 1-3 and 2-3.

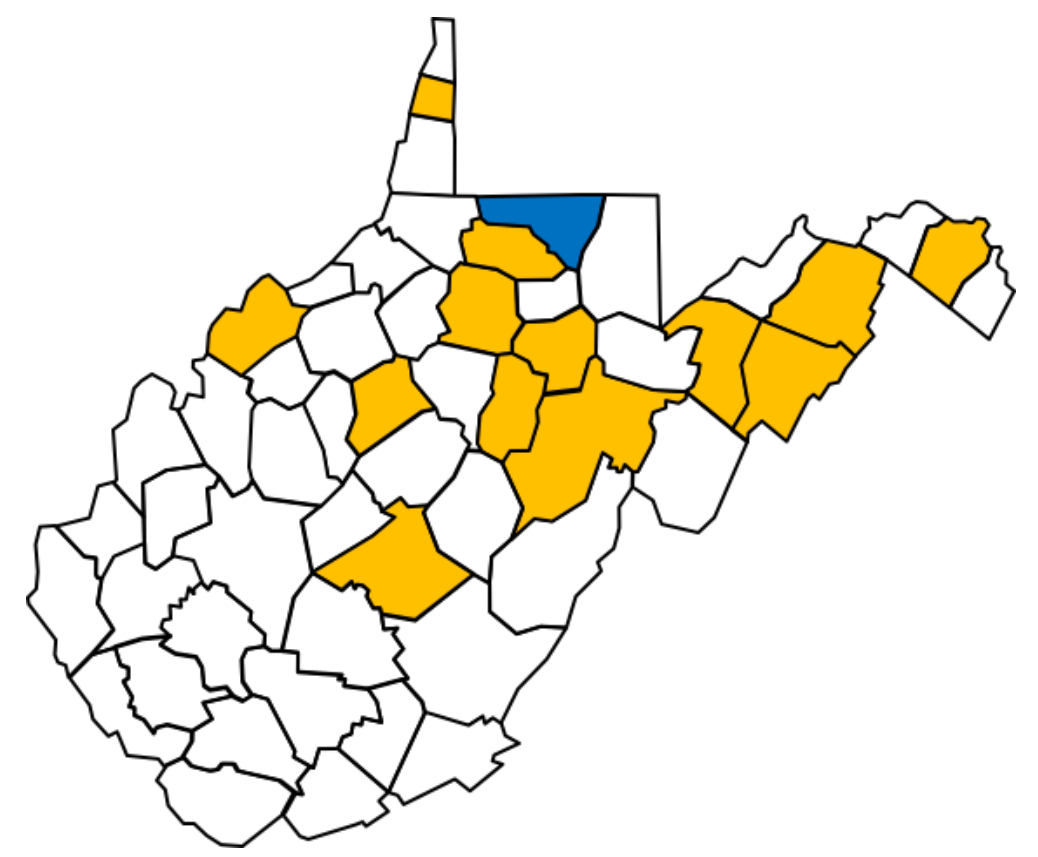

Figure 1-3. West Virginia State Map

1. My child's age is:

2. My child is:
a. Female
b. Male

3. I (parent) am:

a. Female

b. Male

4. What is your ethnicity?

5. I am a resident of City:

County: State:

Figure 2-3. Demographic information questions employed in the survey. 


\section{Background Information.}

This section of the survey gathered background information regarding cleft history and family experience with cleft palate. The questions are presented in Figure 3-3. Of the twentyfour participants surveyed, the distribution of different clefts was the following: eleven had complete unilateral clefts of the primary and secondary palates, two had complete bilateral clefts of the primary and secondary palates, three had a partial cleft of the primary palate with involvement of the alveolus and a complete unilateral cleft of the secondary palate, seven had a cleft of the secondary palate only, and one had a partial cleft of the primary palate with involvement of the lip only.

Four children had a family history of cleft palate, while twenty did not. None of the parents surveyed reported any knowledge or experience with cleft palate prior to their child being born. Eleven of the children were diagnosed with their cleft before birth, ten were diagnosed at the time of their birth, and three were diagnosed after birth. Of the children who were diagnosed after birth, one parent could not recall when the cleft was identified, and one stated that "their child's cleft was found a day after the birth." The third parent reported that her child was not diagnosed with cleft palate until two months of age. The parents of this child had noticed the cleft and made inquiries but were told that the cleft was just a "dimple", which was the result of the insertion of a nasopharyngeal airway. They were further informed that the "dimple" would dissipate spontaneously. When it did not, the parents brought their child to the WVU Cleft Palate Clinic, where a cleft of the secondary palate was formally diagnosed.

6. Do you have a family history of cleft palate?
a. Yes- $17 \%$
b. No- $83 \%$
c. I don't know

7. Did you have any other prior experience with cleft palate before your child was born?
a. Yes
b. No- $100 \%$ 
8. When was your child first diagnosed with a cleft palate?

a. Before birth- $46 \% \quad$ b. Time of birth- $42 \%$

c. After the birth- $12 \%$

Figure 3-3. Background information questions used in the survey

Newborn Feeding

This section of the survey examined the primary investigative question of the early

feeding experiences of the children and their caregivers. The first question was where the parents first received information regarding how to feed their child at the time of birth. Seventeen parents or $70 \%$ of the sample received information from the birth hospital at the time of the child's birth, two children or $8 \%$ were directly transferred to our Health Sciences Center following their birth from more rural hospitals, where the parents then received instruction. One parent (4\%) talked with a physician prior to the birth of her child, and four parents (17\%) received no instruction regarding how to feed their child.

Eleven of the parents $(46 \%)$ received information from a nurse, three from a physician $(13 \%)$, two from a nutritionist $(8 \%)$, three received information from both a nurse and a lactation consultant (13\%), one did not remember (4\%), and four were given no instruction at all (17\%). Four of these parents claimed to be very satisfied with the information they were provided, and eight claimed to be satisfied. Seven parents felt neutral about the information they received, one was dissatisfied, and four were very dissatisfied. Please refer to Figure 4-3. Thirteen of these parents or $54 \%$ of the group surveyed felt it was necessary to seek additional information from other sources as they did not feel prepared to feed their infant. Six parents searched the Internet, three sought information at another hospital, two scheduled a visit with the WVU Cleft Palate Clinic, one contacted West Virginia Birth to Three (Early intervention), and one purchased a book. 


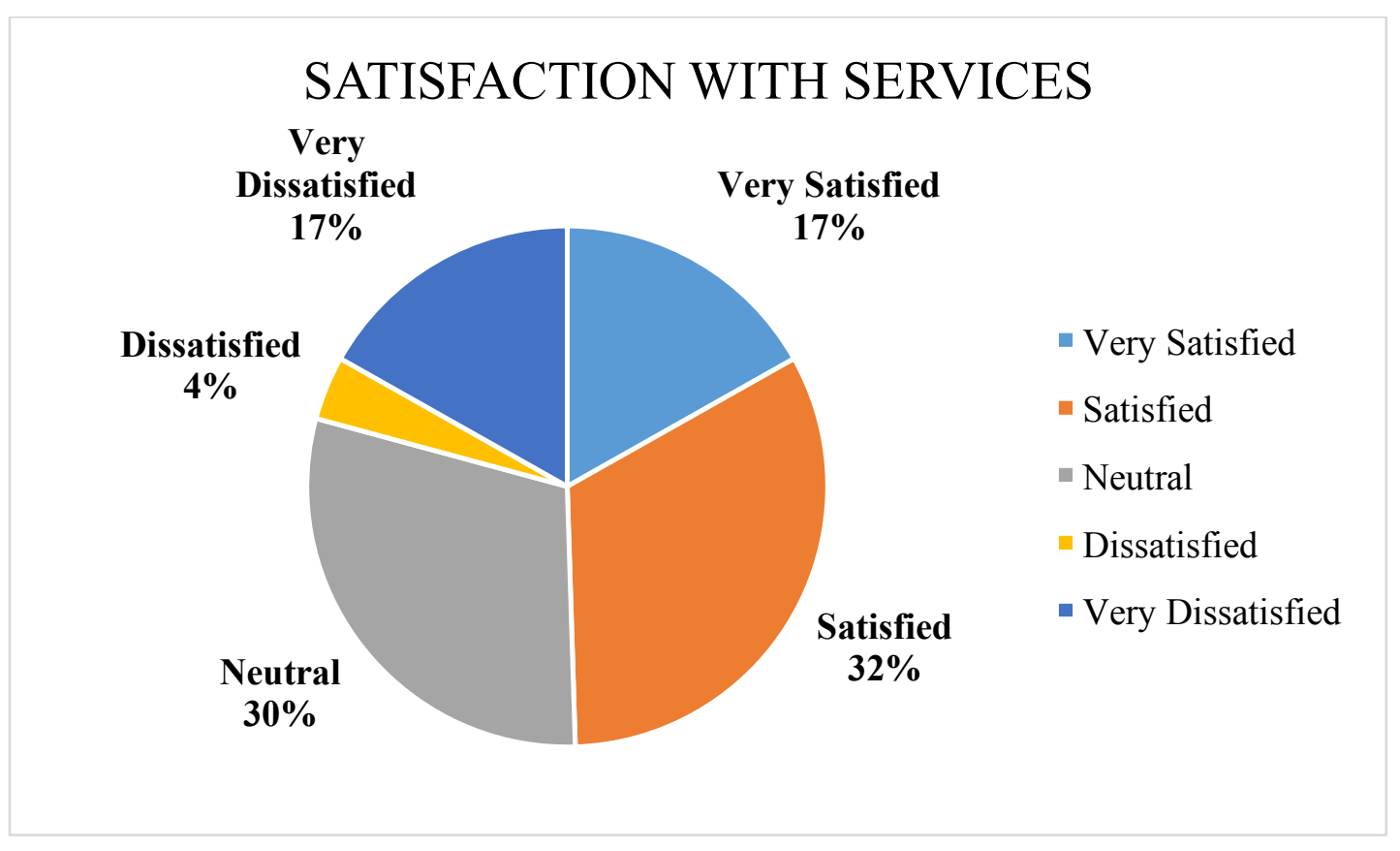

Figure 4-3. Satisfaction with initial services received regarding infant feeding.

\section{Early Feeding Experiences}

The next portion of this section focused on the problems that these babies faced regarding feeding and is summarized in Figures 5-3, 6-3, 7-3, and 8-3. Only one child (4\%) was reported to have no problems with early feeding. The other twenty-three infants (96\%) with clefts were all reported to present with more than one early feeding issue. The reported findings are as follows: thirteen infants had problems latching on the nipple, sixteen babies had a poor suck, nine babies took in a limited quantity of food, and seventeen babies had an extended feeding time. In addition, eighteen babies experienced nasal reflux, nine experienced excessive coughing, twelve had frequent choking, four had frequent vomiting, fourteen had reflux, and eight had bloating. One parent also indicated that her baby had constant oral spill, and one parent noted that their child had excessive sneezing. 


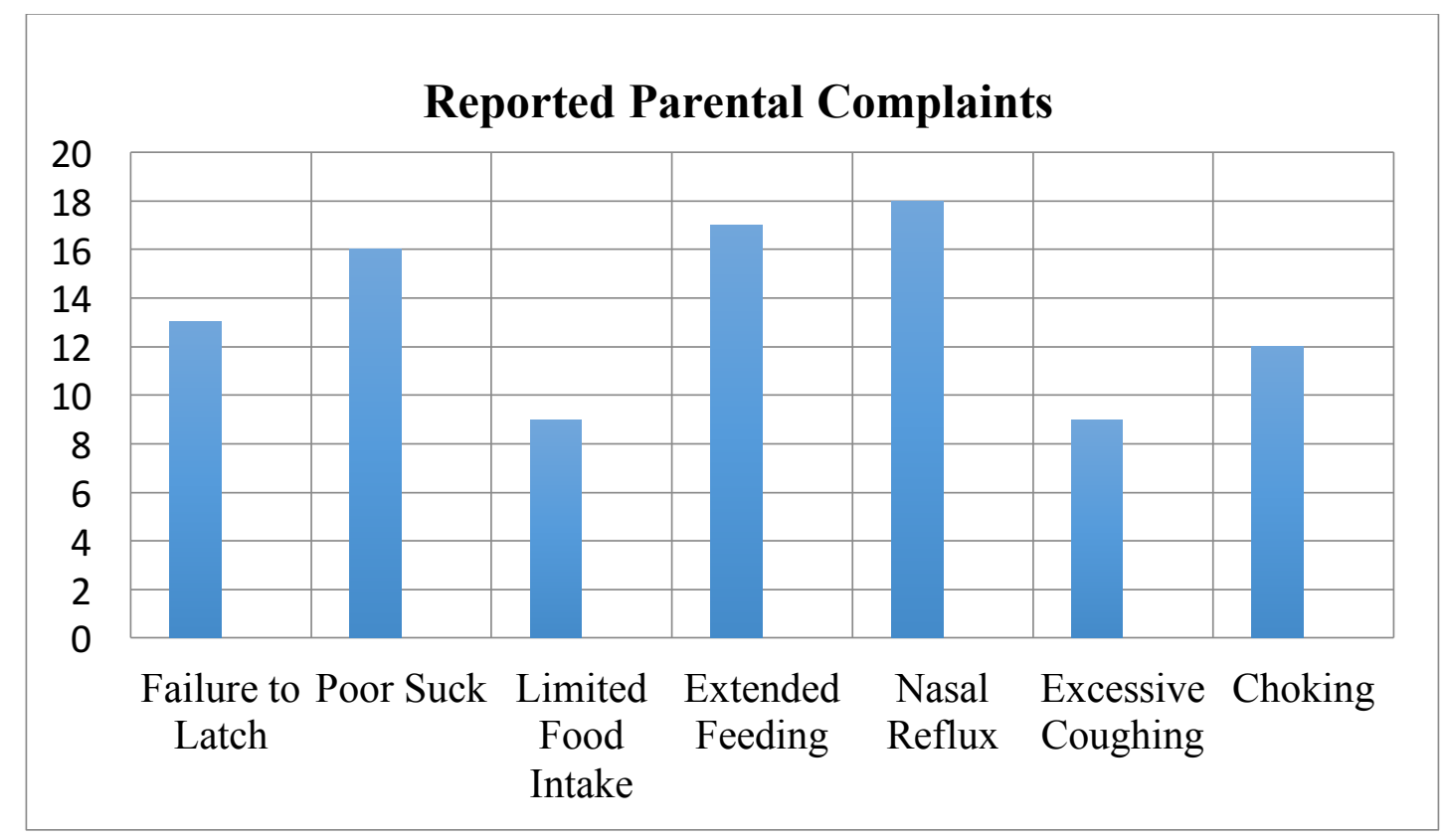

Figure 5-3. Number of reported parental complaints across categories offeeding issues.

The next topic was that of the specific bottling system used and this proved to be one of the most problematic areas reported by parents. Twenty parents were instructed to use a special bottle/nipple by the birth hospital. Three additional parents introduced a special bottle to their child, but they learned of these specialized bottles via Internet searches. In total, twenty-three of the twenty-four surveyed parents utilized a special bottle/nipple with their child. Of the twenty families given a specialty bottle at the birth hospital, ten had been given the Mead Johnson Cleft Palate Nurser, nine were given the Haberman Feeder, and one was given the Dr. Brown bottle at birth. Unfortunately, many parents did not have success with the first bottle they were given. Of the twenty-three parents using specialty bottles, twelve or $52 \%$ reported that they had to try two or more bottling systems before achieving a successful feeding technique. After the trial and error period, five families expressed success with the Mead Johnson Bottle, nine had success with the Dr. Brown bottle, six were successful with the Haberman Feeder, two with the Pigeon 
Bottle, and one reported satisfaction using a Playtex bottle that had a larger nipple. Please refer to Figure 6-3.

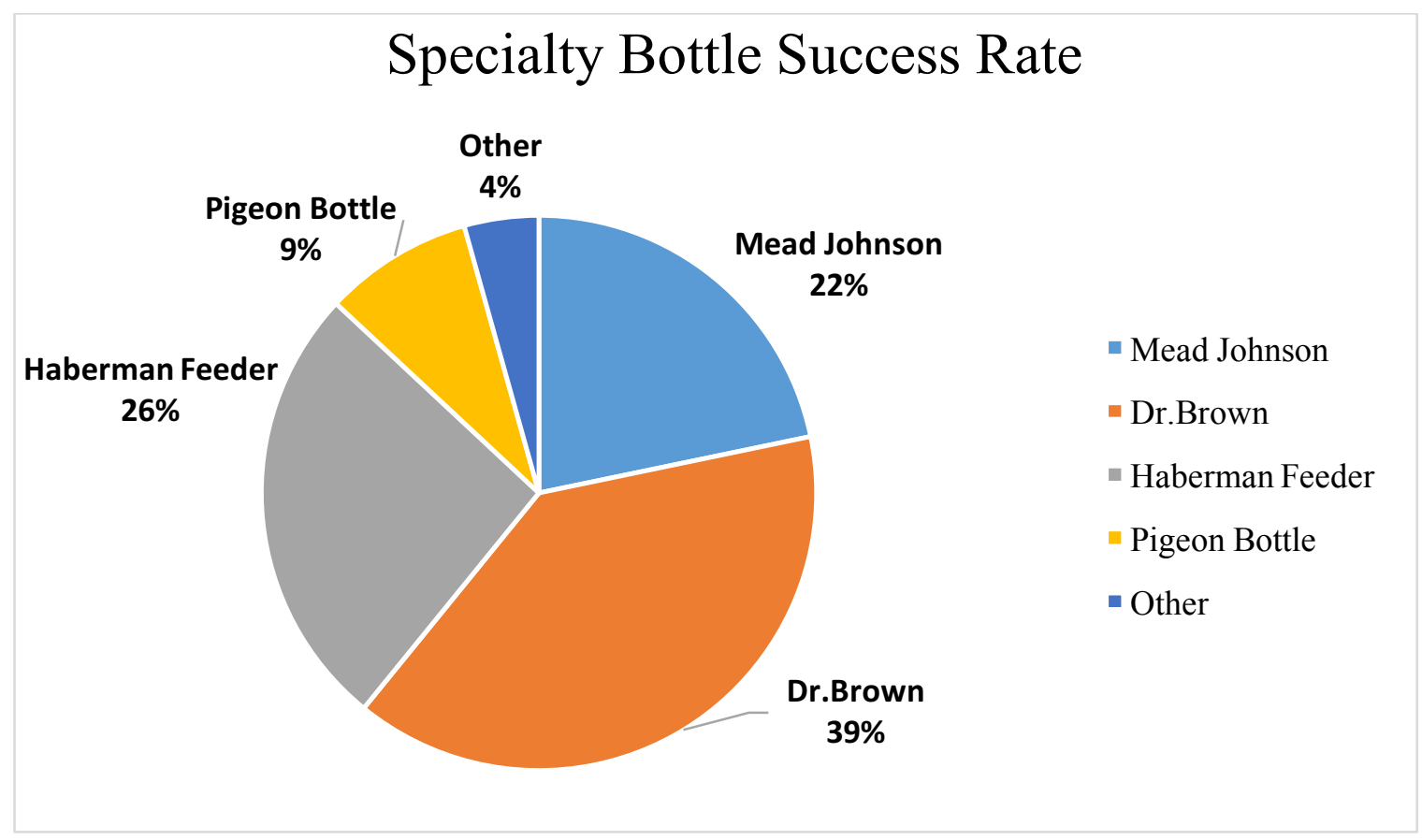

Figure 6-3. Specialty Bottle success rate.

When asking the parents where they received the bottles that gave them success with feeding, ten (43\%) parents expressed that they went online, three (13\%) were able to receive a prescription from their physician, two (9\%) were able to obtain their bottles at a local store, and the other eight (35\%) were able to obtain bottles at their local hospital. Seven of the parents (29\%) surveyed said they had difficulty obtaining these specialty bottles. Reasons for this were due to the extended amount of time it took for them to arrive in the mail, and the fact that some bottles were discontinued. Additionally, five families (21\%) complained about the cost of the bottles.

The last portion of this feeding section examined the weight gain of the newborns. Fifty percent of the parents surveyed stated that it was necessary for them to change their baby's 
formula in order to help them gain weight. Six parents (25\%) also reported that their baby was admitted to the hospital after birth due to a feeding problem. Three babies were admitted due to weight loss, one was admitted because of dehydration, one with constipation, and one due to choking. Overall, two parents claimed they were very satisfied with their child's feeding experience during the first month, nine said they were satisfied, three were neutral, one was dissatisfied, and nine were very dissatisfied. Please see Figure 7-3 for a summary of parental satisfaction.

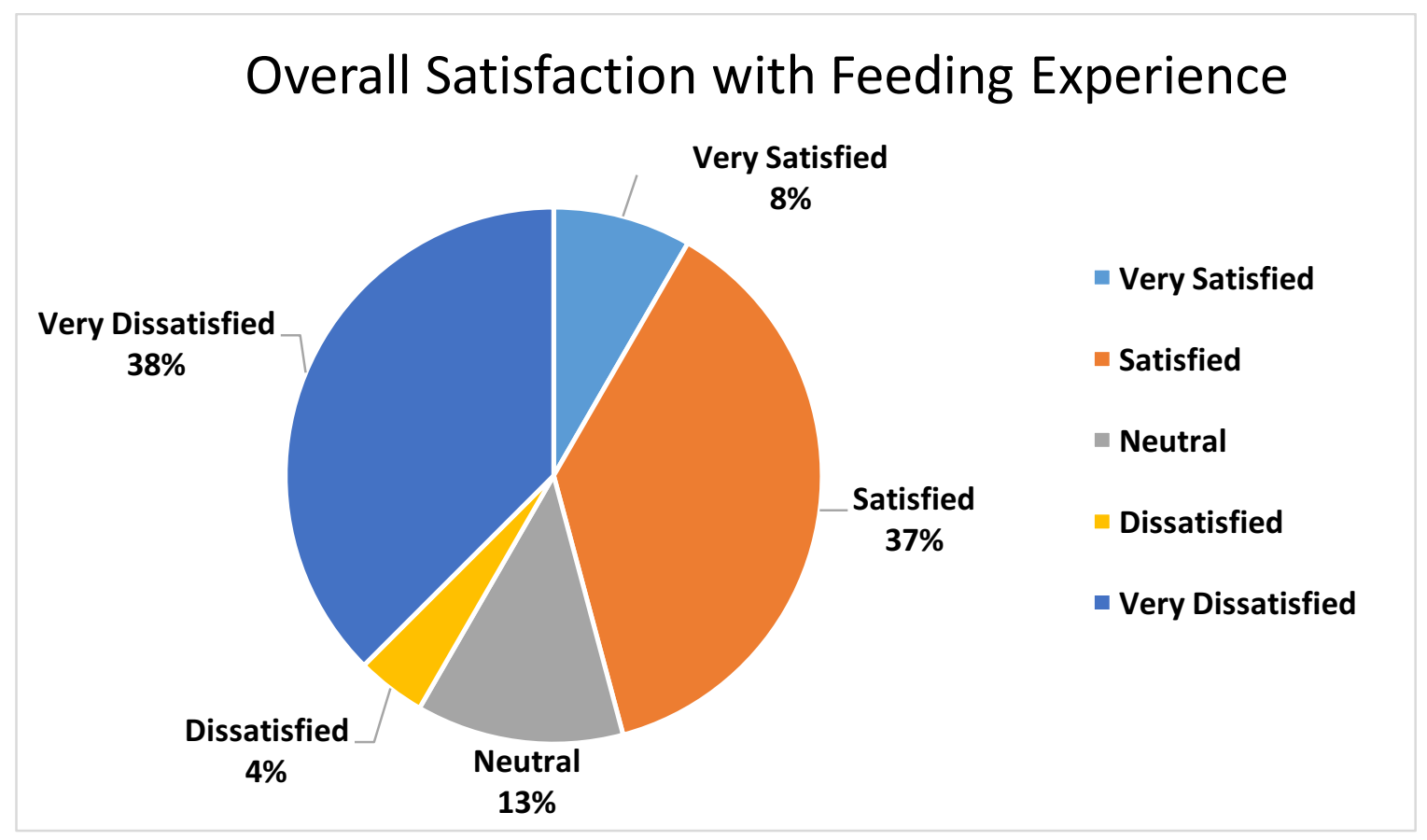

Figure 7-3. Satisfaction with overall feeding experience during first month of birth.

9. At the time of your child's birth, where did you receive information regarding feeding your child?
a. Birth Hospital
b. Cleft Palate Clinic
c. Did not receive instructions
d. Other

10. Which professional(s) provided the feeding instructions at the birth hospital?

(Check all that apply)
a. Nurse
b. Occupational Therapist (OT) 

c. Speech Pathologist (SLP)
d. Physical Therapist (PT)
e. Lactation Consultant
f. Other

11. How satisfied were you with the feeding management information and training you received from the birth hospital?
a. Very Satisfied
b. Satisfied
c. Neutral
d. Dissatisfied
e. Very dissatisfied

12. Was it necessary to seek information from another source?
a. Yes
b. No

If yes, please specify:

13. Did you feel prepared to feed your child after birth?
a. Yes
b. No

14. Did your child experience problems with feeding following birth?
a. Yes
b. No

15. If your baby experienced problems, what were they? Please check all that apply.
a. Did not latch to nipple
b. Poor suck
c. Took a limited quantity of food
d. Extended feeding time
e. Food leaking from the nosef. Excessive coughing
g. Choking
i. Reflux
h. Vomiting
j. Gas

Other:

16. Were you instructed to use a special feeding bottle or nipple?
a. Yes
b. No (If no, skip to Number 20 )

17. What special bottle or nipple did you use? (Choose all that apply)
a. Haberman Feeder
b. Pigeon Feeding Aid
c. Dr.Brown Specialty Bottle d. Mead Johnson Cleft Palate Nurser
e. Not Sure
f. Other(please specify)

18. Where did you obtain these bottles or nipples?
a. Pharmacy
b. Birth Hospital
c. Internet
d. Medical Supply Store
e. Cleft Palate Clinic
f. Other

19. Did you experience difficulty obtaining bottles or nipples?
a. Yes
b. No

Is yes, please specify the reason:

20. Was it necessary to change your baby's formula to help your baby gain weight?
a. Yes
b. No

21. During the first month after birth, was your baby admitted to the hospital because of some feeding problem?
a. Yes
b. No

Is yes, please specify the reason:

22. Overall, how would you describe you and your child's feeding experience during the first month of birth?
a. Very Satisfied
b. Satisfied
c. Neutral
d. Dissatisfied
e. Very dissatisfied 
Figure 8-3. Newborn feeding questions used in the survey.

\section{Breastfeeding}

The next section in the survey sought information regarding breastfeeding, which is always a very controversial issue when dealing with children who present with cleft palate. This section of the survey's questions is displayed in Figure 9-3. Fourteen of the twenty-four respondent families (58\%) considered breastfeeding. Thirteen of these mothers met with a lactation consultant at birth, but only ten of those thirteen were actually encouraged to attempt breastfeeding. Of all families, only one reported successful breastfeeding; however, after one month the infant was diagnosed as failure to thrive (FTT) and was introduced to a bottle. After palatal repair, breastfeeding was again introduced and the infant was reported to suck without problem. One mother reported that she was encouraged to breastfeed her baby, even though she had inverted nipples and felt that she could not physically breastfeed.

\section{Did you consider breast-feeding?}
A. Yes
b. No (If no, skip to Number 27)

24. Did you meet with a lactation consultant after the birth of your child to attempt breastfeeding?
a. Yes
b. No
c. Not sure

25. Were you encouraged to breastfeed your baby?
a. Yes
b. No

26. If yes, were you successful with breastfeeding?
a. Yes
b. No

Figure 9-3. Breastfeeding questions used in the survey.

\section{WVU Cleft Palate Clinic}

The final section of the survey discussed the parent's experience with the WVU Cleft Palate Clinic (See Figure 10-3). The Cleft Palate Clinic is one of two in West Virginia; 
consequently, families must often travel a significant distance to receive services. Fourteen of the parents or $58 \%$ reported that they received assistance with their feeding needs at the WVU Cleft Palate Clinic. The other ten respondents (42\%) indicated that they had no feeding issues by the time they came to the clinic. Overall, eight parents (33\%) stated to be very satisfied with the feeding management information and training they received from the clinic, and six (25\%) stated to be satisfied.

27. When you first visited the Cleft Palate Clinic, was your child's feeding status discussed?
a. Yes
b. No

28. Did the cleft palate team assist you with any feeding needs?
a. Yes
b. No
c. Did not have feeding needs

29. If there was a feeding issue, how satisfied are you with the feeding management information and training you received from the cleft palate team?
a. Very Satisfied
b. Satisfied
c. Neutral
d. Dissatisfied
e. Very dissatisfied

Figure 10-3. WVU Cleft Palate Clinic Satisfaction questions used in the survey.

\section{Additional Comments}

Once the survey was complete, an additional section was included to solicit parent comments about any issues that families encountered and felt the need to comment. Fifteen of the twenty-four parents or $63 \%$ had additional comments regarding their experience.

A consistent complaint that was seen in this anecdotal section was the confusion among professionals concerning bottle-feeding at outlying medical facilities. One mother indicated that no staff members knew how to feed her child. She tried six different bottles along with syringe feeding until something worked. Another mother explained that she was given the Mead Johnson Cleft Palate Nurser at the birth hospital, but was given no instruction how to use it. No one at the 
hospital knew that it was an assisted feeding bottle and the feeder needed to squeeze the bottle. It resulted in her baby not receiving an adequate amount of formula. The mother conducted an Internet search and found the Dr. Brown bottle online, which she ordered. It took four days to receive the bottles and by that time her son had already lost $1 \mathrm{lb}$. and $2 \mathrm{oz}$. Another mother told us that she was given no instruction at all on feeding. It was not until her baby was diagnosed as FTT and was put into the NICU that she received information. The information that she did receive came from a nurse who worked in another department of the hospital but learned of the problem and provided feeding information, because her child was born with a cleft palate.

Another very interesting anecdote came from a family whose child was born in another rural hospital. She stated that she had an ultrasound performed at the hospital prior to birth, whereupon her daughter's cleft was diagnosed. However, at the time of birth, none of the hospital personnel had any knowledge of the cleft diagnosis and were surprised when the infant was born with a cleft. The mother expressed that she was extremely upset that this important information was never transferred to her medical chart prior to the birth of her daughter. Following the birth, the child experienced extreme problems with oral spill due to the size of her cleft lip. However, the doctors claimed that she was allergic to milk and that's why she was "spitting up". The mother reports that her daughter is not allergic to milk, and the problem was resolved as soon as the lip was repaired. Another mother from the same geographic area voiced extreme disappointment in the treatment of her newborn as well. This mother explained that when asked for information regarding her baby's cleft palate, the doctor told her to "search the Internet." Her baby had lost over $1 \mathrm{lb}$. in 2 weeks due to not receiving an adequate amount of nutrition via a bottle. 
Another story told by a parent was concerning the delayed diagnosis of her baby's cleft. The cleft was left undiagnosed until 2 months of age. The parents had spotted the cleft shortly after birth but were told it was a "dimple from a feeding tube", and that it would disappear in time. The parents had gone to two different local hospitals and a family physician before the cleft was properly diagnosed and they were referred to the WVU Cleft Palate Clinic.

Finally, a consistent topic that came up with many parents was the need for a support group. Many parents expressed that they felt very alone in this process and would have benefited from talking to other parents who went or were going through a similar situation. One mother expressed her concern for breastfeeding support by saying "Breast milk is not impossible! It just takes a lot of time and effort. There needs to be more assistance for moms who want to pump \& also assistance with affording bottles." One mother told us that everyone at the hospital was afraid to feed her son and that the only help she received was from a nurse who had a son born with a cleft. She told us it was a "long hard ride" and she wished there was more support out there for parents. 


\section{Chapter 4: Discussion}

This survey examined parental perceptions of their children's early feeding experiences. Since these children were born with orofacial clefts, initial feeding can be problematic and the findings reported herein certainly support this position. Overall many parents experienced problems that reflected a lack of education and training on the part of those individuals who interacted with the families upon the birth of the child. The discussion will cover the components of the survey, and one must keep in perspective that children with cleft palate constitute a low incidence group and as such are not seen on a frequent basis. This problem appears to be even more acute in birthing hospitals located in rural areas.

\section{Demographics}

A number of studies (Hutchinson, 2005; Oliver \& Jones, 1997; Shuttlesworth, 2015; Sree Devi, 2012; Trenouth \& Campbell, 1996; Young, 2001) have examined the feeding management of infants with cleft lip and/or palate; however, this is the first to our knowledge that has surveyed families who reside in a rural locale. West Virginia is one of only 15 rural states in America (U.S. Census Bureau, 2010), and our investigation included participants in 15 counties within the state. Hospitals in these locations do not have a large number of births, and would likely see an even more limited number of births of children with cleft palate. The respondents of our sample certainly confirm that information and instruction were lacking for parents who needed to feed their infants. For instance, one mother surveyed stated that she was given no instruction at all on feeding, resulting in her baby being diagnosed as FTT and admitted to the NICU. Others indicated that only partial information was given regarding how to feed their infants, which resulted in a number of different problems that were encountered when they initially engaged in feeding. 


\section{Background Information}

It is interesting to note that of the parents who participated in the survey, none reported prior experience/exposure to cleft palate. Although our sample size was limited $(n=24)$, this lack of experience/exposure is not an uncommon report among parents. For example, Shuttlesworth (2014) surveyed 179 parents and found that only $20 \%$ had experience and/or knowledge of cleft palate prior to their child's birth. This finding along with our data indicate the need for hospital personnel to have an understanding of the expression of cleft palate in the general population and the management of newborns with a cleft that can be shared with the parents. In a majority of cases, however, it appears that hospital personnel had limited or no experience in the management of children with clefts and were not able to educate parents. Our findings support the position that parents and hospital personnel need access to information that will assist both parties in understanding the implications of cleft palate on feeding and other feeding-related issues.

\section{Newborn Feeding}

According to the parents surveyed, $70 \%$ of them stated that they received information regarding feeding at the birth hospital. These results are somewhat comparable to that of Hutchinson (2005), who found that $59 \%$ of parents in her study received their feeding information from the birth hospital. It appears that most frequently, the nurse is the primary information provider to families regarding feeding. Our study found that $59 \%$ of parents spoke with a nurse regarding initial feeding, Hutchinson's is comparable at 53.09\%, and Oliver and Jones (1997) at 40\%. Other professionals in lesser frequency who relayed information were physicians, lactation consultants, and nutritionist. Ironically, not one SLP relayed information to parents regarding feeding in this study, or the other two studies that were cited. It is surprising 
that hospitals are not involving the SLP in this treatment stage considering their academic background and training in the areas of both cleft lip and palate and pediatric feeding.

The American Speech-Language-Hearing Association (ASHA) which governs SLPs in the United States defines a practitioner as:

“A speech-language pathologist is responsible for the diagnosis, prognosis, prescription, and remediation of speech, language, and swallowing disorders. A speech-language pathologist evaluates and treats children and adults who have difficulty speaking, listening, reading, writing, or swallowing. The overall objective of speech-language pathology services is to optimize individuals' ability to communicate and swallow, thereby improving quality of life" (American Speech-Language-Hearing Association, 2016).

However, in some cases, the lack of training and experience may also be a factor for the SLP, since many do not have course work or hands-on experience in the management of cleft palate. The above statement is consistent with findings discussed by Bedwinek, Rice, and Grames (2007), who found that $60 \%$ of SLP's surveyed $(n=332)$ have seen $0-2$ children with a cleft in their caseloads; affirming the need for accessible, accurate information. Nevertheless, we recommend that an SLP be involved in the early feeding interactions with the family, because they should be able to identify appropriate sources of information and evidence to assist the parents and the child.

The gap in knowledge and perception of parents regarding this gap in knowledge was quite evident in their responses, since $51 \%$ of parents surveyed claimed to be dissatisfied with the services received at the hospital. Similarly, Oliver \& Jones (1997) found that $61 \%$ of parents they surveyed were not satisfied with the information given to them at their hospital. In addition, 
Trenouth and Campbell (1996) reported that almost all mothers in their study were disappointed with the information they received at the birth hospital. The dissatisfaction of parents is a general finding across studies. In our sample, the dissatisfaction resulted in $54 \%$ of parents reporting that it was necessary for them to seek sources outside of the hospital for information regarding feeding their infants.

\section{Early Feeding Experiences}

Only one parent claimed to have no problems when initiating feeding with her child. The other $96 \%$ of the respondents described multiple complaints. The top three complaints found were nasal regurgitation ( $75 \%$ of children), extended feeding time (71\% of children), and insufficient suction (67\% of children). In a study conducted by Sree Devi and his associates (2012), it was found that $73 \%$ of infants with a cleft palate had moderate to severe feeding difficulties. The most notable problems seen were insufficient suction, excessive air intake, choking, nasal regurgitation, fatigue, inadequate milk intake, failure to gain weight, and excessive time required to feed. The findings of Sree Devi are directly comparable to the feeding difficulties found in our study. Moreover, these feeding issues are routine problems that are frequently present in children with clefts and information to parents at the time of birth would probably reduce anxiety and improve feeding interactions (Zajac, 2017).

Identifying a bottle and/or nipple that provided success proved to be a challenge for the majority of the parents who participated in our study. The majority of our parents $(83 \%)$ were directed to use a specialty bottle at the birth hospital; however, over half of these parents had to find an alternative bottle in order to achieve successful feeding. It is clear that bottle feeding management is a crucial issue for parents of babies with clefts and the finding is similar to that reported in other studies (Young, O'Riordian, Goldstein, \& Robin, 2001). Young indicated that 
97\% of families thought it was "critical" for the feeding management provider to discuss bottle feeding difficulties and 95\% believed it was "critical" to have a demonstration of bottle feeding. We agree and also feel that some of our parents were given information about different bottles but not in the principles of how the bottles allow the flow of formula. That is, the bottles and nipples were designed to facilitate sufficient flow and some parents reported that they were not informed. For example, the Mead-Johnson Enfamil Cleft Palate Nurser is a low-cost alternative bottle. It has a soft, long, cross-cut (x-shaped) nipple that attaches to a squeezable bottle. This bottle requires assisted squeezing by the caregiver, which may allow for more precision in the flow rate and amount of formula (Miller \& Kummer, 2008). This assumption was supported in our anecdotal section, when a mother explained that she was given the Mead Johnson bottle by her hospital, but was not instructed in its use. Hospital personnel did not know that it was an assisted feeding bottle and that the feeder needed to squeeze the bottle. This resulted in the infant not receiving an adequate amount of formula. Therefore, while it may seem elementary, instruction in use is critical when using a specialized feeding system.

\section{Breastfeeding}

Although $60 \%$ of the mothers surveyed reported that they considered breastfeeding, less than half attempted to breast feed. None of the respondents indicated that they were able to exclusively breast feed their baby. This finding is consistent with Trenouth and Campbell (1996), who reported that of their 25 mothers surveyed, none had success with breastfeeding. While it is frequently problematic, breast milk is preferred and should be considered; however, in the case of cleft palate, breast milk needs to be delivered via some special bottling/nipple system (Zajac, 2017; Vallino, 2017). 


\section{WVU Cleft Palate Clinic}

When analyzing the satisfaction rate of the feeding services at the WVU Cleft Palate Clinic, all parents surveyed claimed to be satisfied or very satisfied. The reader must keep in mind that the WVU Cleft Palate clinic is a fully functioning clinic providing all of the necessary services and professionals that children with cleft palate need. Jeffery and Borman (2000) asked the same question regarding their clinic and received similar results; $96 \%$ of parents reported they were satisfied or very satisfied with services at their cleft palate clinic. The services provided at a cleft palate clinic are multi-disciplinary in nature and clients and families receive assistance from a group of professionals. Within this multidisciplinary approach is also the experience and expertise of personnel who have worked with these children for an extended period of time. In addition, many of the children were seen after their feeding problems had resolved. We feel that it is incumbent upon professionals to have the appropriate knowledge and skills to work effectively with this population, particularly in the area of early feeding acquisition and development. The limitations in service that we identified need to be addressed and one element that will aid rural healthcare professionals is an informational component that provides the necessary information that can be shared with families.

\section{Limitations}

There are some limitations inherent to this study that need to be discussed.

1. The sample size was limited, but it should be noted that the responses of the parents in this study and other studies were quite consistent in terms of their reported early feeding experiences with their children.

2. Recall bias may be a limiting factor present in the study. Recall bias is a common issue seen in studies that rely on self-reporting. It is likely some parents may have forgotten details about their 
child's feeding experience or reported them to an inaccurate degree. This is especially true with the parents whose children are in the upper age range of our study (Coughlin, 1990).

3. Due to the nature of the study, it is important to recognize that this is a regional study in a rural locale, and these findings may not be generalizable to urban and suburban areas.

Nevertheless, trends were identified and are consistent with other healthcare issues identified in rural areas.

\section{Summary}

The data reported in this study underscores the need for parental assistance in the feeding management of children with cleft palate. It was very clear in the analysis of the responses that the information most parents needed to conduct satisfactory feeding was not provided to them. It is crucial that an SLP or other appropriately trained professional assist in the feeding management of infants born with cleft palate with the long-term care being managed by an interdisciplinary team. Adequate education on bottle and breast feeding is crucial, and every hospital should have a variety of specialty bottles on hand to aid in determining which one facilitates successful feeding. Healthcare professionals, who do not have access to adequate cleft palate training, need resources available to them that they can reference should a baby be born with a cleft. In response to the findings, an informational pamphlet was developed for distribution to all hospitals in the state of West Virginia. The pamphlet presented in Appendix C covers the following areas:

1. A brief explanation of cleft palate and the expression of clefting in the population.

2. An explanation of feeding and problems that may be experienced by the child and family.

3. Feeding techniques that may be employed to develop appropriate skills.

4. The selection of appropriate nipples and bottles for the child. 
5. Internet resources for parents and professionals. 


\section{Appendix A: Consent Form}

\section{Only Minimal Risk \\ Consent Information and HIPAA Form}

Principal Investigator

Department

Protocol Number

Study Title

Co-Investigator(s)
Meghan Snyder

Communication Sciences and Disorders

11571

Early feeding experiences of families whose children were born with cleft palate Dennis Ruscello, Ph.D

\section{Contact Persons}

Meghan Snyder, B.S

In the event you experience any side effects or injury related to this research, you should contact Meghan Snyder at (717)829-4270. If you have any questions, concerns, or complaints about this research, you can contact should contact Meghan Snyder at (717)-829-4270.

For information regarding your rights as a research subject, to discuss problems, concerns, or suggestions related to the research, to obtain information or offer input about the research, contact the Office of Research Integrity and Compliance at (304) 293-7073.

In addition if you would like to discuss problems, concerns, have suggestions related to research, or would like to offer input about the research, contact the Office of Research Integrity and Compliance at 304-293-7073.

\section{Introduction}

You, , have been asked to participate in this research study, which has been explained to you by Meghan Snyder or Dr.Ruscello. This study is being conducted by Meghan Snyder in the Department of Communication Sciences and Disorders at West Virginia University with funding provided by

\section{Purpose(s) of the Study}

The purpose of the proposed study is twofold. First, the feeding experiences of families whose children were born with cleft lip and palate or cleft palate only will be studied. The respondents will consist of families who attend the WVU Cleft Palate Clinic. They will be asked to complete a survey regarding their early feeding experiences. Second, their responses will be analyzed and if feeding issues are identified, an informational feeding program will be developed to assist personnel in helping parents and their children with feeding issues.

\section{Description of Procedures}

You will be asked to fill out a questionnaire regarding early feeding experiences of parents with their children born with a cleft palate. This will take approximately 15 minutes. You do not have to answer all the questions. You will have the opportunity to see the questionnaire before signing this consent form.

\section{Discomforts}

There are no known or expected risks from participating in this study, except for the mild frustration associated with answering the questions.

\section{Alternatives}

You do not have to participate in this study. 


\section{Benefits}

You may not receive any direct benefit from this study. The knowledge gained from this study may eventually benefit others.

\section{Financial Considerations}

There are no special fees for participating in this study.

\section{Confidentiality}

Any information about you that is obtained as a result of your participation in this research will be kept as confidential as legally possible. Your research records and test results, just like hospital records, may be subpoenaed by court order or may be inspected by the study sponsor or federal regulatory authorities without your additional consent.

In any publications that result from this research, neither your name nor any information from which you might be identified will be published without your consent.

\section{HIPAA}

We know that information about you and your health is private. We are dedicated to protecting the privacy of that information. Because of this promise, we must get your written authorization (permission) before we may use or disclose your protected health information or share it with others for research purposes.

You can decide to sign or not to sign this authorization section. However, if you choose not to sign this authorization, you will not be able to take part in the research study. Whatever choice you make about this research study will not have an effect on your access to medical care.

\section{Persons/Organizations Providing the Information}

You as the participant in the study.

\section{Persons/Organizations Receiving the Information}

The research site carrying out this study, which includes WVU and the research staff.

\section{The Following Information Will Be Used}

Demographic information and questionnaire response.

\section{The Information is Being Disclosed for the Following Reasons}

Publication of study results (without identifying you)

\section{You May Cancel this Authorization at Any Time by Writing to the Principal Investigator} Meghan Snyder, B.S

7711 Fishing Creek Valley Rod

Harrisburg, Pa 17112

meghansny24@yahoo.com

If you cancel this authorization, any information that was collected already for this study cannot be withdrawn. Once information is disclosed, according to this authorization, the recipient may redisclose it and then the information may no longer be protected by federal regulations.

You have a right to see and make copies of your medical records. You will not be able to see or copy your records related to the study until the sponsor has completed all work related to the study. At that time you may ask to see the study investigator's files related to your participation in the study and have the study investigator correct any information about you that is wrong. 
This authorization will expire at the end of the study unless you cancel it before that time.

\section{Voluntary Participation}

Participation in this study is voluntary. You are free to withdraw your consent to participate in this study at any time.

Refusal to participate or withdrawal will not affect the quality of care you receive at the WVU Hospitals. Refusal to participate or withdrawal will not affect your future care, or your employee status at West Virginia University. In the event new information becomes available that may affect your willingness to participate in this study, this information will be given to you so that you can make an informed decision about whether or not to continue your participation.

You have been given the opportunity to ask questions about the research, and you have received answers concerning areas you did not understand.

Upon signing this form, you will receive a copy.

I willingly consent to participate in this research.

\section{Signatures}

Signature of Subject

The participant has had the opportunity to have questions addressed. The participant willingly agrees to be in the study.

Signature of Investigator or Co-Investigator 


\section{Appendix B: Survey}

\section{Instructions}

Dear Parent:

We are interested in learning about your experiences with feeding your child when she/he was just born at the hospital. We kindly ask you to take a few minutes to complete this survey. The information you give us will help us better serve other families who have infants with cleft lip and palate in the future. It is important for you to know that neither you nor your child will be identified. Thank you for taking the time to complete this survey.

\section{Section I: Demographic Information}

1. My child's age is:

2. My child is:
a. Female
b. Male

3. I (parent) am:
a. Female
b. Male

4. What is your ethnicity?

5. I am a resident of City: County: State:

\section{Section II: Background Information.}

6. Do you have a family history of cleft palate?
a. Yes
b. No
c. I don't know

7. Did you have any other prior experience with cleft palate before your child was born?
a. Yes
b. No 
8. When was your child first diagnosed with a cleft palate?
a. Before birth
b. Time of birth
c. After leaving the birth hospital

\section{Section III: Newborn Feeding}

9. At the time of your child's birth, where did you receive information regarding feeding your child?
a. Birth Hospital
b. Cleft Palate Clinic
c. Did not receive instructions
d. Other

10. Which professional(s) provided the feeding instructions at the birth hospital? (Check all that apply)
a. Nurse
b. Occupational Therapist (OT)
c. Speech Pathologist (SLP)
d. Physical Therapist (PT)
e. Lactation Consultant
f. Other

11. How satisfied were you with the feeding management information and training you received from the birth hospital?
a. Very Satisfied
b. Satisfied
c. Neutral
d. Dissatisfied
e. Very dissatisfied

12. Was it necessary to seek information from another source?
a. Yes
b. No

Is yes, please specify the reason:

13. Did you feel prepared to feed your child after birth?
a. Yes
b. No

14. Did your child experience problems with feeding following birth? 

a. Yes
b. No

15. If your baby experienced problems, what were they? Please check all that apply.
a. Did not latch to nipple
b. Poor suck
c. Took a limited quantity of food
d. Extended feeding time
e. Food leaking from the nose
f. Excessive coughing
g. Choking
h. Vomiting
i. Reflux
j. Gas

Other:

16. Were you instructed to use a special feeding bottle or nipple?
a. Yes
b. No (If no, skip to Number 20\)

17. What special bottle or nipple did you use? (Choose all that apply)
a. Haberman Feeder
b. Pigeon Feeding Aid
c. Dr.Brown Specialty Bottle d. Mead Johnson Cleft Palate Nurser
e. Not Sure
f. Other (please specify)

18. Where did you obtain these bottles or nipples?
a. Pharmacy
b. Birth Hospital
c. Internet
d. Medical Supply Store
e. Cleft Palate Clinic
f. Other

19. Did you experience difficulty obtaining bottles or nipples?
a. Yes
b. No

Is yes, please specify the reason:

20. Was it necessary to change your baby's formula to help your baby gain weight?
a. Yes
b. No 
21. During the first month after birth, was your baby admitted to the hospital because of some feeding problem?
a. Yes
b. No

Is yes, please specify the reason:

22. Overall, how would you describe you and your child's feeding experience during the first month of birth?
a. Very Satisfied
b. Satisfied
c. Neutral
d. Dissatisfied
e. Very dissatisfied

\section{Section IV: Breastfeeding}

23. Did you consider breast-feeding?
A. Yes
b. No (If no, skip to Number 27)

24. Did you meet with a lactation consultant after the birth of your child to attempt breastfeeding?
a. Yes
b. No
c. Not sure

25 . Were you encouraged to breastfeed your baby?
a. Yes
b. No

26. If yes, were you successful with breastfeeding?
a. Yes
b. No 


\section{Section V: WVU Cleft Palate Clinic}

27. When you first visited the Cleft Palate Clinic, was your child's feeding status discussed?
a. Yes
b. No

28. Did the cleft palate team assist you with any feeding needs?
a. Yes
b. No
c. Did not have feeding needs

29. If there was a feeding issue, how satisfied are you with the feeding management information and training you received from the cleft palate team?
a. Very Satisfied
b. Satisfied
c. Neutral
d. Dissatisfied
e. Very dissatisfied

If there is any additional information that you would like to add, please feel free to do so.

Thank you for your participation. 


\section{Appendix C: Informative Pamphlet}

\section{Cleft Lip/Palate $\&$ Feeding}

A brief overview of early care for parents, caregivers, and professionals who care for or provide services to infants with cleft palate

BY MEGHAN SNYDER

\section{Table of Contents}

What is Cleft Lip and/or Palate?............................ 1

Frequent Problems............................... 2

Feeding Suggestions........................... 3

Specialty Bottles............................. 4

Specialty Bottles Cont. ........................5

Resources ....................................6 


\section{What is Cleft Lip/Palate?}

Cleft lip and/or cleft palate is the most common facial anomaly in newborn infants, affecting one in every 500 to 1,000 births worldwide. A cleft occurs during the early stages of pregnancy when the tissues and bones of the mouth are fusing together to form the upper lip and hard and soft palates. There is no single cause of clefts, as there are a number of factors that can be responsible.

A cleft can present in a variety different ways, such as a cleft of just the lip, a cleft of just the palate, or a cleft of the lip and palate. A child's cleft can be unilateral, where it is just on one side (ie. on the left side of the face or the ride side) or bilateral, where it is on both. Clefts of the palate can be primary, where they appear from the lip to hard palate (ie. the front portion of the palate), or secondary, where they occur at the boney roof of the mouth and soft palate (ie. the back portion of the palate). Many children can also present with a cleft of both the primary and secondary palates.

Clefts of the lip and/or palate can appear in a variety of forms, which can make it challenging for parents and caregivers to find a straightforward plan of care to follow. This pamphlet will discuss different problems you may face, feeding techniques you can try, and bottles you can use. The purpose is to provide guidance during this transitional time. The back of this pamphlet also has resources you can use to access more information regarding cleft lip and/or palate.

\section{Frequent Problems}

1. Breastfeeding. Typically, breast feeding is difficult for bab with clefts. Often breast feeding will work well if the cleft is c lip only. The nipple may conform and fill the area of the cleft. mother can assist with closing off the lip with her hands. If the is confined to just the soft palate, the infant may also be able $t$ breastfeed to an extent using the hard palate to make compres: Infants with a complete cleft are much more likely to have a d time with breast feeding due to the fact they will be unable to negative pressure for suction. If a mother wants to try breastfe it is important to closely monitor the baby to ensure that she/h receiving sufficient nutrients, or the mother can pump breast $r$ and present via one of the delivery systems discussed.

2. Nasal Regurgitation. Often babies with clefts have food cc out of their nose. This is referred to as nasal regurgitation. It is important to note that this is not dangerous and does not mean baby is in distress.

3. Poor Suck. Babies with clefts frequently have a difficult ti1 establishing a suckle-and-swallow sequence due to the lack of pressure caused by the opening of the cleft. It may require a tr and-error period to try out different bottling systems and figur what works best for the baby.

4.Air Intake. Infants with clefts generally take in air when thr eating. This can cause gas buildup if not relieved by frequent burping. 


\section{Suggestions for Feeding}

\section{The primary goals of feeding are}

- Establish satisfactory feeding within 2-5 days of birth.

- Feeding time for the baby should take approximately $20-40$ minutes. Infants with clefts often have to work very hard during feedings, and they may even burn more calories than they take in from breast milk or formula. If they have to work too hard weight gain is a problem.

- A key feeding goal is satisfactory weight gain of at least 7 ounces per week after the first week of life. You want to be sure that your baby gains weight to grow and develop her/his body and brain.

\section{Other Techniques You Should Employ Are...}

- Establish an appropriate feeding position. While feeding, keep your baby in an upright position at an angle of about 45 to 90 degrees. This will help prevent choking, gagging and nasal reflux. Also, try to keep her/his chin tucked toward the chest. This improves the suck and reduces the amount of air swallowed.

- Place the nipple away from the cleft. If possible, angle the nipple away from the cleft- side of the mouth. This may reduce gagging. Do not place the nipple inside the cleft.

- Burp your baby frequently. Infants with clefts take in air when they swallow their food. It is helpful to burp your baby about every 15 minutes during and after feedings.

- Keep your baby in an upright position after feedings. Wait 20 to 30 minutes after feeding before you let your baby lie down. This helps reduce the chances of the baby spitting up.

\section{Specialty Bottles}

To ensure the flow of formula, special bottles and nipples are available for children with CL/P. The nipples system with speci; bottles deliver an increased rate of formula flow to the infant or allow the feeder to manually assist the infant by squeezing the bottle or nipple.

\section{Types of Specialty Bottles}

\section{Dr. Brown}

The Dr. Brown's Specialty Feeding System is a special bottle/nipple/valve system. It may be beneficial for infants and bottle-fed children identified with poor sucking problems, This bottle is low cost and unique because it has an internal venting system, which eliminates nipple collapse and promotes a positiv flow. Nipples are available in different sizes and flow rates, thus an infant can gradually increase the rate of formula flow

\section{Mead Johnson Enfamil Cleft Palate Nurser}

This is a soft squeeze bottle with long cross cut nipple. Designec to be "pulse" squeezed with baby's suck and swallowing. The longer nipple allows milk to be directed past 


\section{Resources}

e cleft and cross cut allows increase flow with squeezing. UK and premie nipples also work well on this bottle. The Jles on these nipples may need to be made larger to allow milk flow faster.

\section{[aberman Feeder}

his bottle has a long squeezable nipple with slit instead of cross It and valve which allows milk to flow into a inverted nipple Id not back into bottle. Another feature is the gauge on the side the nipple ring to set for desired rate of flow. The Haberman mes in two nipple sizes, mini or regular.

\section{igeon Bottle by Respironics}

his bottle is soft, but not easy to squeeze plastic. The nipple has $\mathrm{Y}$-cut with a firm top and a softer bottom to allow for easier ngue compression. It also has an air valve so that milk will כw into the nipple and not back into bottle. A bottle ring can be ljusted to change flow rate.
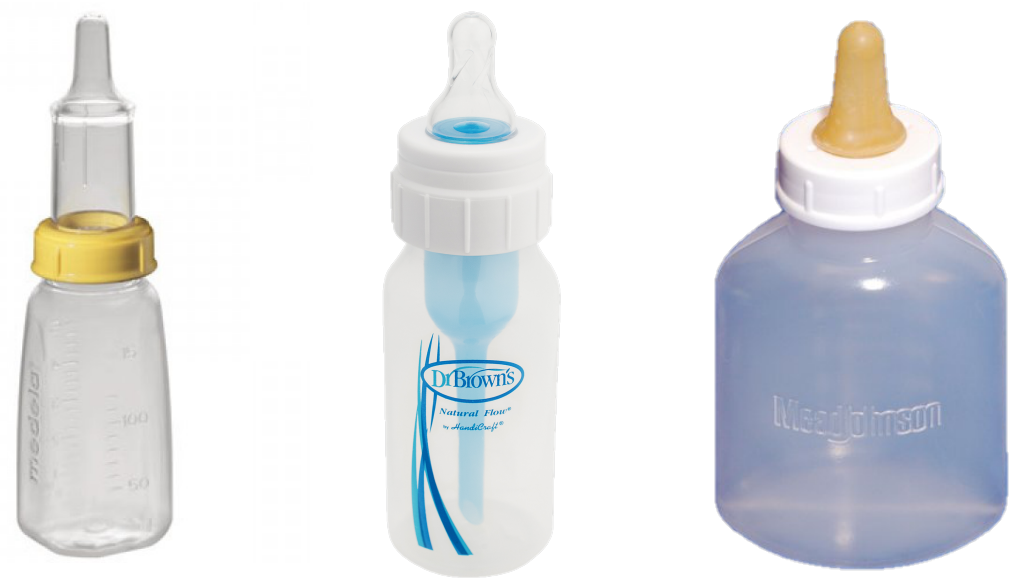

Below are some resources you can utilize to learn more about cleft lip and/or palate and how you can help your baby grow and develop

\section{American Cleft Palate - Craniofacial Association}

- http://www.acpa-cpf.org/

\section{Cleft Palate Foundation}

- (800)24-Cleft

- http://www.cleftline.org/

Online video demonstrations of different bottles

- $\quad$ http://www.cleftline.org

\section{Quick Facts and Resources:}

- Center for Disease Control \& Prevention https://www.cdc.gov/ncbddd/birthdefects/cleftlip.html

- Mayo Clinic

- http://www.mayoclinic.org/diseases-conditions/cleftpalate/basics/definition/con-20024619

If you are a parent in the state of West Virginia or surrounding area and would like to schedule a visit to the WVU Cleft Palate Clinic please contact us as 304-598-4825

This pamphlet was created by Meghan Snyder as part of a master's thesis through the Department of Communication Sciences and Disorders at West Virginia University under the direction of Dr. Dennis Ruscello. 


\section{$\underline{\text { Works Cited }}$}

American Speech-Language-Hearing Association. (2016). Scope of practice in speech-language pathology. Retrieved from ASHA: http://www.asha.org/policy/SP2016-

00343/?utm_source=asha\&utm_medium=enewsletter\&utm_campaign=accessslp030916

Bedwinek, A., Rice, G., \& Grames, L. (2007). An analysis of needs: The school speech-language pathologist and the child with cleft lip/palate. Retrieved from ASHA:

https://www.google.com/url?sa=t\&rct=j\&q=\&esrc=s\&source=web\&cd=2\&cad=rja\&uact=8\&ve d=0ahUKEwi4_dv46pjTAhVlK8AKHUBrAjYQFggrMAE\&url=http\%3A\%2F\%2Fgradworks.u mi.com\%2F32\%2F89\%2F3289566.html\&usg=AFQjCNGwaD11WqPvdL5-9-K3r-mqvqcR0A

Blood, G., Thomas, E., Ridenour, J., \& Hammer, C. (2002). Job stress in speech-language pathologist working in rural, suburban, and urban schools: Social support and frequency of interactions. Contemporary Issues in Communication Science and Disorders, 29, 132-140.

Borgan, W., Foulner, D., \& Turner, R. (1987). A videoradiographic investigation of the position of tongue prior to palatal repair in babies with cleft lip and palate. The Cleft Palate-Craniofacial Journal, 24, 224-249.

Callaghan, A., McAllister, L., \& Wilson, L. (2005). Barriers to accessing rural pediatric speech pathology service: Health care consumers' perspectives. Australian Journal of Rural Health, 13, $162-171$.

Center for Disease Control and Prevention. (2015, Novemeber 12). Facts about cleft lip and cleft palate. Retrieved from Centers for Disease Control and Prevention: http://www.cdc.gov/ncbddd/birthdefects/cleftlip.html 
Coleman, T. J., Thompson-Smith, T., Pruitt, G. D., \& Richards, L. N. (1999). Rural service delivery: Unique challenges, creative solutions. ASHA, 41, 40-50.

Coughlin, S. (1990). Recall bias in epidemiologic studies. Journal of Clinical Epidemiology, 43(1), 8791.

Gil-da-Silva-Lopes, V., Xavier, L., Klein-Antunes, D., Ferreira, A., \& Tonocchi, R. (2013). Feeding infants with cleft lip and/ or palate in Brazil: Suggestions to improve health policy and research. The Cleft Palate-Craniofacial Journal, 50, 577-590.

Handi-Craft Company. (2017). Bottle Feeding. (Handi-Craft, Producer) Retrieved from Dr.Brown Baby: https://www.drbrownsbaby.com/

Hansen, P., Cook, B., \& Ahmad, O. (2016). Fabrication of a feeding obturator for infants. The Cleft Palate-Craniofacial Journal. 53, 240-244.

Houn, B., \& Troitter, K. (2003). Meeting the challenge of rural service delivery. Retrieved from The ASHA Leader: http://leader.pubs.asha.org/article.aspx?articleid=2292322

Hutchinson, D. (2005). Assessment of parental satisfaction with management of a child's nonsyndromic cleft lip and/or cleft palate. University of Cincinnati, Genetic Counseling. Ann Arbor: ProQuest Information and Learning Company.

Jeffery, S., \& Boorman, J. (2001). Patient satisfaction with cleft lip and palate services in a regional centre. British Journal of Plastic Surgery 54, 189-191.

Kernahan, D., \& Stark, R. (1958). A new classification for cleft lip and cleft palate. Plastic and Reconstructive Surgery and the Transplantation Bulletin. 22, 435-431.

Liu, Q., Yang, M., Li, Z., Bai, X., Wang, X., \& Wang, Y. (2007). A simple and precise classification for cleft lip and palate: A five-digit numerical recording system. Cleft Palate-Craniofacial Journal, 44(5), 465-468 
Masarei, A. (2003). The effect of presurgical orthopedics on feeding infants with cleft lip and palate. London: University College London.

McKusick, V. (1998). Mendelian inheritance of man. In A Catalog of Human Genes and Genetic Disorders (Vol. 12). Baltimore: John Hopkins Univeristy Press.

Mednick, L., Snyder, J., Schook, C., Blood, E., Brown, S., \& Weatherley-White, R. (2013). Casual attributions of cleft lip and palate across cultures. The Cleft Palate - Craniofacial Journal, 50(6), $655-661$.

Millard, R. (1980). The naming and classifying of clefts. In Cleft Craft: The Evolution of its Surgery (Vol. 1, p. 1232). Boston: Brown Little.

Miller, C., \& Kummer, A. (2008). Feeding problems of infants with cleft lip/palate or craniofacial anomalies. In A. Kummer, Cleft palate and craniofacial anomalies: Effects on speech and resonance (pp. 115-126). New York: Thomson Delmar Learning.

Murray, J. (1995). Face facts: Genes, environment, and clefts. American Journal of Human Genetics, 57, 227-232.

Nagaoka, K., \& Tanne, K. (2007). Activities of the muscles involved in swallowing patients with cleft lip and palate. Dysphagia, 22, 140-144.

Oliver, R., \& Jones, G. (1997). Neonatal feeding of infants born with cleft lip and/or palate: Parental perceptions of their experience in South Wales. Cleft Palte-Craniofacial Journal, 34(6), 526530.

Orlikoff, R., Schiavetti, N., \& Metz, D. (2015). Evaluating research in communication disorders. Boston: The Pearson Communication Sciences and Disorders Series.

Peterson-Falzone, S., Hardin-Jones, M., \& Karnell, M. (2010). Cleft Palate Speech. St. Louis, Missouri: Mosby Elsevier. 
Reid, J. (2004). A review of feeding interventions for infants with cleft palate. The Cleft PalateCraniofacial Journal, 41(3), 268-278.

Richard, M. E. (1994). Weight comparison of infants with complete cleft lip and palate. Journal of Pediatric Nursing, 20, 191-196.

Shuttlesworth, E., Dalton, L., \& Cooper, M. (2014). Developing a measure of appraisal: A psychometric analysis of the parental appraisal of cleft questionnaire. The Cleft Palate-Craniofacial Journal. $51,207-221$.

Sree Devi, E., Sai Sankar, A., Manoj Kumar, M., \& Sujatha, B. (2012, December). Maiden morsel feeding in cleft lip and palate infants. Journal of International Society of Preventive and Community Dentistry, 2(2), 31-37.

Strasser, R. (2003). Rural health around the world: Challenges and solutions. Family Practice, 20, 457463.

Tolarova, M., \& Cervenka, J. (1998). Classifications and birth prevalence of orofacial clefts. American Journal of Medical Genetics, 75, 126-137.

Trenouth, M., \& Campbell, A. (1987). A new feeder for infants with cleft palates. Archives of Disease in Childhood, 62, 1292-1293.

Trenouth, M., \& Campbell, A. (1996). Questionnaire evaluation of feeding methods for cleft lip and palate neonates. International Journal of Pediatric Dentistry. 6, 241-244.

U.S. Census Bureau. (2010). 2010 Census Urban and Rural Classification and Urban Area Criteria. Retrieved from United State Census Bureau: https:/www.census.gov/geo/reference/ua/urbanrural-2010.html

Vallino, L. (2017). Clefts of the lip and palate. In D. Zajac, \& L. Vallino, Evaluation and Managament of Cleft Lip and Palate (pp. 23-47). San Diego, CA: Plural Publishing. 
Young, J., O'Riordian, M., Goldstein, A., \& Robin, N. (2001). What information do parents of newborns with cleft lip, palate, or both want to know? Cleft Palate - Craniofacial Journal, 38(1), 55-58.

Zajac, D. (2017). Feeding the newborn. In D. J. Zajac, \& L. Vallino, Evaluation and Managament of Cleft Lip and Palate (pp. 113-128). San Diego: Plural Publishing Inc.

Zickefoose, M. (1957). Feeding problems of children with cleft palate. Cleft Palate-Craniofacial Journal, 4, 225-228. 